\title{
The undrained shear strength anisotropy of four Jurassic to Eocene stiff clays
}

\section{A. M. BROSSE* ${ }^{*}$ R. J. JARDINE $\dagger$ and S. NISHIMURA $†$}

\begin{abstract}
The shear strength of heavily overconsolidated, stiff-to-hard plastic clays is crucial to their stability and also influential on the ground movements they develop in many geotechnical engineering applications. This paper considers the shear strength anisotropy of the London, Gault, Kimmeridge and Oxford clays through advanced hollow cylinder experiments on multiple high-quality samples taken at similar depths from inland sites where the geotechnical profiles have been established by comprehensive laboratory and in situ testing. Suites of undrained tests are reported, which loaded specimens from their in situ stress states to reach ultimate failure at pre-defined final major principal stress axis orientations defined in the vertical plane, while also controlling or monitoring the intermediate principal stress ratio, $b$. Both stress path and simple shear tests were undertaken with the hollow cylinder apparatus, which offers key advantages over conventional simple shear equipment. The interpretation reveals patterns of marked shear strength anisotropy that impact significantly on numerous geotechnical engineering applications.
\end{abstract}

KEYWORDS: anisotropy; clays; laboratory tests; shear strength; stress path

\section{INTRODUCTION}

Much of the UK's civil engineering infrastructure and several major cities are built on stiff, overconsolidated, geologically aged, high-overconsolidation-ratio (OCR) plastic clays, which can be remarkably brittle in shear. Slope instability is frequently encountered in such clays, particularly in coastal areas. Progressive failure is common, in which the shear surface microstructure reorients towards low-shear-strength, residual conditions; see Morgenstern \& Tchalenko (1967) or Potts et al. (1997). These features also render stability assessment difficult with deep excavations, foundations, tunnels, cut slopes, embankments and dams; see, for example, Potts et al. (1990). Representative information on shear strength behaviour from peak to ultimate conditions is vital to current UK developments that will cross high-OCR, stiff, plastic clay strata, including the main north-south high-speed rail line (HS2) and at least one new nuclear power station.

Natural stiff clays often manifest directionally oriented macro- to microstructures (Hight et al., 2007; Hosseini Kamal et al., 2014). Tectonic shears and fissure discontinuities can affect their mass shear strength profoundly. Assuming isotropy in shear strength and assuming that peak triaxial compression shear strengths apply in all cases could be misleading in clays that are either anisotropic or brittle when sheared.

Shear strength and its anisotropy can also affect the displacements developed in engineering works where ground movement considerations dominate design. Geotechnical structures can develop zones of contained failure under

$\overline{\text { Manuscript received } 13 \text { October 2015; revised manuscript accepted }}$ 11 January 2017.

Discussion on this paper is welcomed by the editor.

* Geotechnical Consulting Group, London, UK; formerly Imperial

College London, London, UK (Orcid:0000-0003-3496-2550).

$\dagger$ Department of Civil and Environmental Engineering, Imperial

College London, London, UK (Orcid:0000-0001-7147-5909).

* Faculty of Engineering, Hokkaido University, Sapporo, Hokkaido, Japan. fully stable, small-displacement conditions that, together with the often anisotropic non-linear stiffness of the soil mass, control the overall patterns and scales of ground movements (Lo, 1965; Jardine et al., 1986; Addenbrooke et al., 1997; Potts \& Zdravkovic, 2001; Jardine et al., 2005).

Hight \& Jardine (1993) demonstrated the importance of: (a) high-quality sampling; (b) addressing natural structure; and (c) applying appropriate effective stress states when characterising stiff clay behaviour. Fig. 1(a) reproduces the shear failure envelopes they established from large numbers of $K_{0}$ reconsolidated undrained triaxial compression tests on rotary and block samples of London clay, showing an en-echelon family of curved surfaces that expanded upwards with sample depth. Samples taken from any individual depth showed marked reductions in the stress ratio $t / s^{\prime}$ at peak shear strength when consolidated to effective stresses greater than those acting in situ and the opposite when swelled to lower stresses. The simple $c^{\prime}=0, \phi^{\prime}=19^{\circ}$ criterion provided a lower bound for all samples that failed on pre-existing planar fissure discontinuities aligned at angles near to the optimum $45^{\circ}-\phi^{\prime} / 2$ orientation from the vertical at which $\tau / \sigma_{n}^{\prime}$ is greatest under active triaxial conditions. Gasparre et al. (2007a) report similar patterns from triaxial tests conducted on high-quality London clay specimens from a wide depth range at the Heathrow T5 site. After normalising the peak $q-p^{\prime}$ stresses by the Hvorslev equivalent mean effective stresses $p_{\mathrm{e}}^{*}$, as defined by oedometer tests performed on reconstituted specimens from similar depths, they concluded that the clay's state boundary surfaces varied with depth in the similar en-echelon sequence reproduced in Fig. 1(b).

The Oxford, Kimmeridge, Gault and London clay formations considered in this study comprise high-OCR clays deposited between the Jurassic and the Eocene in broadly similar marine environments. Sampling depths around $10 \mathrm{~m}$ below the clays' current eroded surfaces were selected at the inland sites identified in Fig. 2 to reduce the potential local effects of prior tectonic disturbance, post-depositional weathering, glacial or tree action. High-quality block and Geobor-S rotary cored samples were taken at each site. Experiments on Gault, Kimmeridge and Oxford clays formed part of the integrated study detailed by Wilkinson 


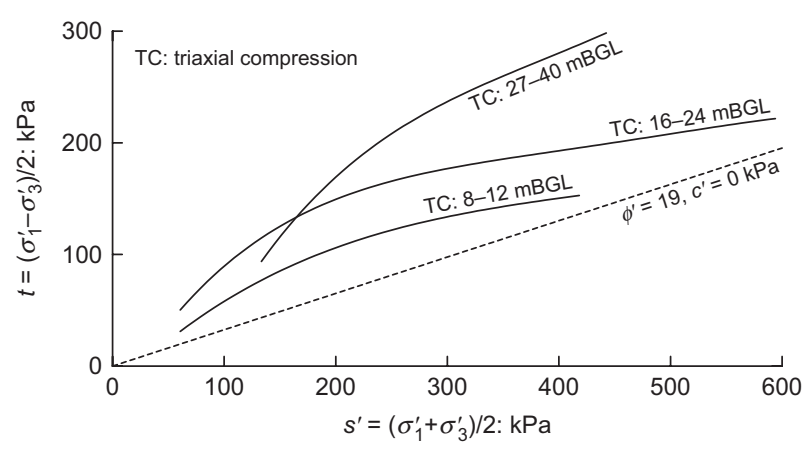

(a)
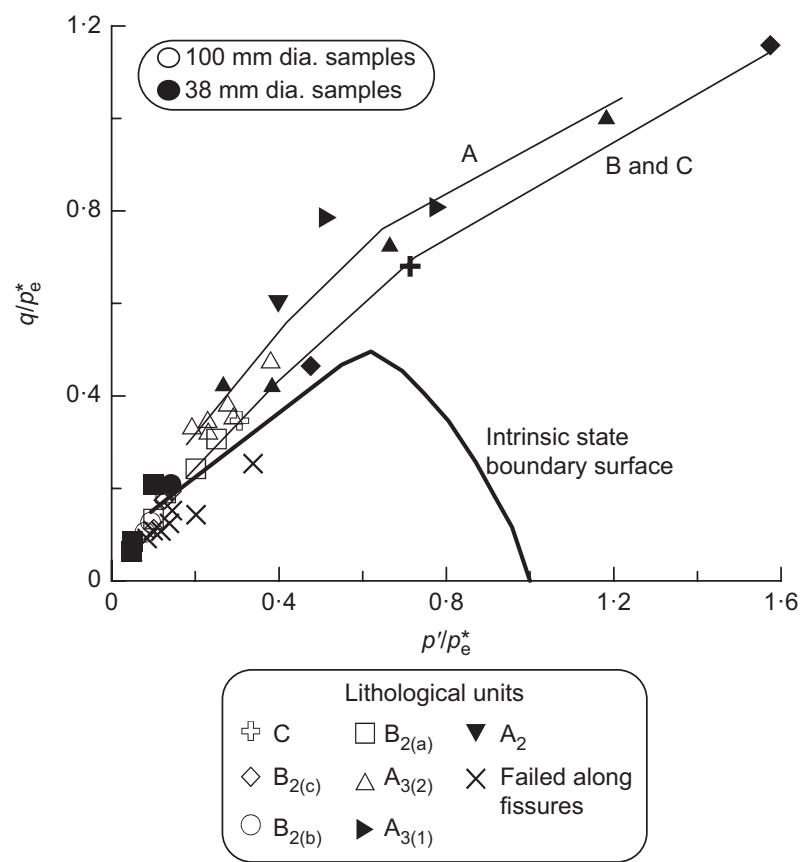

(b)

Fig. 1. (a) Shear strength envelopes for London Clay derived from triaxial compression (TC) tests, after Hight \& Jardine (1993). The $c^{\prime}=0, \phi^{\prime}=19^{\circ}$ line represents the fissure shear strength. (b) Normalised shear strength envelopes for London Clay derived from TC tests, after Gasparre et al. (2007a)

(2011), Brosse (2012) and Hosseini Kamal (2012); Hosseini Kamal et al. (2014) presented full geotechnical profiles for each site and reported on the in situ testing undertaken at each location. The London Clay hollow cylinder apparatus (HCA) experiments were performed as part of the Heathrow Terminal 5 study; Hight et al. (2007) provided full details of this site's geotechnical profile.

Tables 1 and 2 summarise key aspects of the four clays' descriptions, micro- and meso-fabrics, index properties and estimated in situ effective stresses. None of the clays presented macrostructural features such as clearly visible laminations or tectonic shear bands. Their mesostructures include features such as fissures or bedding planes that are visible by eye, yet small enough for their effects to be homogenised and perceived as characteristics of representative soil 'elements'. Also listed are the peak triaxial compressive undrained shear strengths, $S_{\mathrm{u}}$, obtained from carefully $K_{0}$ reconsolidated, $100 \mathrm{~mm}$ dia. specimens and residual angles of shearing resistance, as determined in ring shear experiments. The Oxford clay samples had the clearest bedding features, but no fissures, and developed markedly higher triaxial compression shear strengths and post-peak brittleness. The peak triaxial shear strengths of natural samples of the other clays were
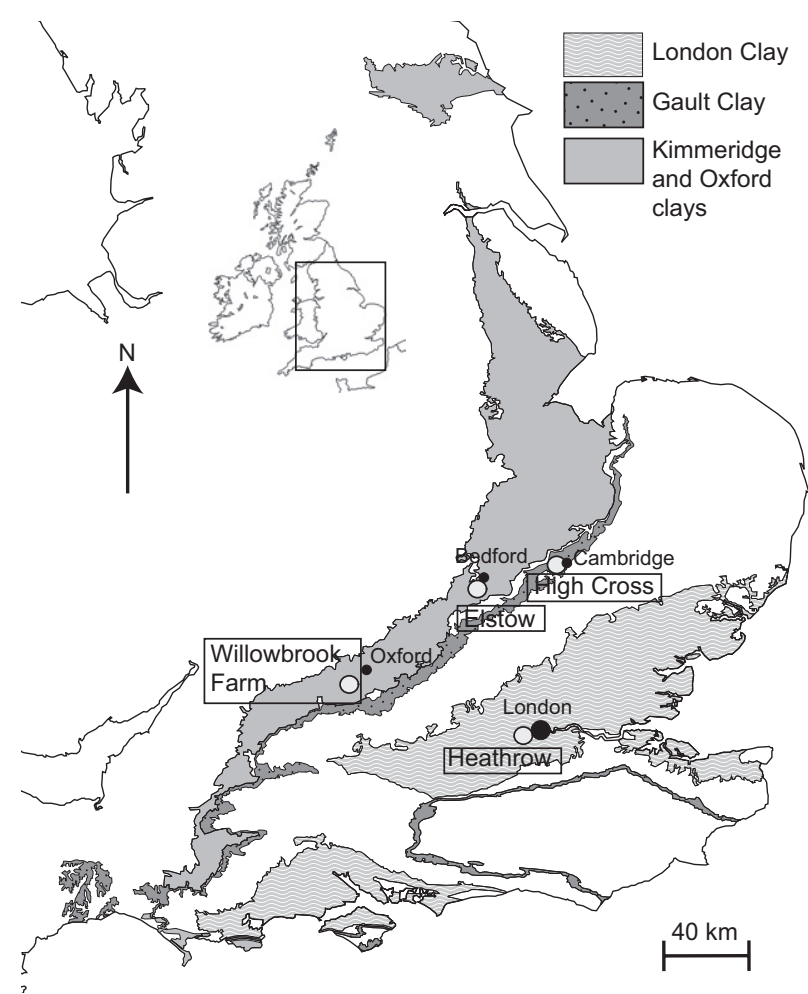

Fig. 2. Location map of the studied material sampling sites, modified from Brosse (2012). The Kimmeridge Clay outcrop is a thin band bordering the south of the Oxford Clay outcrop so that the two have been combined on the map

strongly affected by their greater fissure intensity. All four soils are markedly brittle in shear. Hosseini Kamal et al. (2014) discuss the sample sizes required to conduct tests with representative element volumes (REVs) and report, perhaps surprisingly, no clear correlation between the clays' large strain behaviours and their variable ages or maximum prior burial depths. After removing as far as possible the potential effects of other depositional and post-depositional factors, they concluded that mesostructure was the most important determinant of the natural clays' large-scale yielding behaviour under triaxial conditions.

This paper explores the four clays' shear strength anisotropy as established by two types of HCA experiments on high-quality natural specimens. The first type loaded specimens from in situ stresses to failure at a range of final major principal stress axis orientations (defined as $\alpha$ the orientation of the $\sigma_{1}$ axis to the vertical), while also maintaining fixed intermediate principal stress conditions. The second comprised simple shear HCA tests on samples tested from in situ and other effective stress conditions. Nishimura (2006), Nishimura et al. (2007, 2008) and Brosse (2012) provide further details of the experiments and interpretation, while Brosse et al. $(2016,2017)$ report on the four clays' highly non-linear, pressure-dependent and anisotropic pre-failure stiffness characteristics.

\section{APPARATUS AND PROCEDURES}

Principles

Hollow cylinder apparatus tests can be employed to investigate the directional dependency, or anisotropy, of soil properties by varying independently the axial force $(F)$, torque $(T)$ and inner and outer cell pressures ( $p_{\mathrm{i}}$ and $p_{\mathrm{o}}$, respectively) applied to test specimens. These boundary changes allow operators to control the average vertical, radial, circumferential 
and torsional shear stresses $\sigma_{z}, \sigma_{\mathrm{r}}, \sigma_{\theta}$ and $\tau_{z \theta}$, as illustrated in Fig. 3. Provided that a uniform pore pressure $u$ can be maintained in fully drained tests, the effective stresses $\sigma_{z}^{\prime}, \sigma_{\mathrm{r}}^{\prime}$ and $\sigma_{\theta}^{\prime}$ may also be varied as required. Hight et al. (1983) explained how the control is achieved physically and derived the expressions listed in Table 3 to relate the average sample strains and total stresses to the boundary measurements. The latter, which have been widely adopted since then as standard protocols for HCA operation and interpretation, have been applied in this study. HCA systems maintain $\tau_{z \mathrm{r}}=\tau_{\mathrm{r} \theta}=0$ and provide four degrees of freedom that offer independent control of the $p, q, \alpha\left(\right.$ or $\left.\alpha_{\mathrm{d} \sigma}\right)$, and $b$ stress parameters defined as

$$
\begin{aligned}
& p=\frac{\left(\sigma_{1}+\sigma_{2}+\sigma_{3}\right)}{3} \\
& q=\sigma_{1}-\sigma_{3} \\
& \alpha=\frac{1}{2} \tan ^{-1}\left(\frac{2 \tau_{z \theta}}{\sigma_{z}-\sigma_{\theta}}\right) \\
& \alpha_{\mathrm{d} \sigma}=\frac{1}{2} \tan ^{-1}\left(\frac{2 \mathrm{~d} \tau_{z \theta}}{\mathrm{d} \sigma_{z}-d \sigma_{\theta}}\right) \\
& b=\frac{\sigma_{2}-\sigma_{3}}{\sigma_{1}-\sigma_{3}}
\end{aligned}
$$

$\alpha$ is the angle between the direction of the major principal stress $\sigma_{1}$ and the vertical, whereas $\alpha_{\mathrm{d} \sigma}$ is the direction of the axis of the major principal stress increment. The effective stresses (denoted by ') are obtained simply by subtracting the measured or imposed pore pressure, $u$. Establishing the effects of $\alpha$ alone on material behaviour provides a direct way of investigating shear strength anisotropy. Variations in the $\tau_{z \theta}-\left(\sigma_{z}-\sigma_{\theta}\right) / 2$ plane can be studied by conducting multiple tests that adopt fixed intermediate principal stress ratios $b$ between 0 and 1 .

\section{Equipment}

The two computer-controlled HCA systems illustrated in Figs 4 and 5 and described by Nishimura et al. (2007), Minh et al. (2011) and Brosse (2012) were employed. Both can apply mixed stress and strain control. The nominal outer diameters, inner diameters and heights of their test specimens were $70 \mathrm{~mm}, 38 \mathrm{~mm}$ and $170 \sim 190 \mathrm{~mm}$ for the Imperial College resonant column hollow cylinder apparatus (ICRCHCA) and $100 \mathrm{~mm}, 60 \mathrm{~mm}$ and $200 \mathrm{~mm}$ for the Imperial College hollow cylinder apparatus mark II (ICHCA II). Hosseini Kamal et al. (2014) discuss the impact of the samples' meso-fabric and discontinuity spacings on laboratory shear strength measurements, showing that the HCA specimens were sufficiently large to provide broadly REVs.

The ICRCHCA is equipped with a Hardin torsional resonant column oscillator to obtain dynamic $G_{z \theta}$ shear moduli. Sample deformation was measured globally, apart from the semi-local (platen-to-platen) torsional rotations, which were sensed with a proximity transducer system. The ICHCA II employed a full suite of high-resolution local transducers. Axial displacements and torsional rotations were measured with enhanced electro-level inclinometers, while changes of the inner and outer radii were measured with a linear variable differential transducer (LVDT) and three proximity transducers, respectively. The average stresses were calculated according to Table 3 from the current sample dimensions, as updated from global displacement 
Table 2. Basic index and strength properties

\begin{tabular}{l|c|c|c|c|r|r}
\hline Soil & Water content: $\%$ & Plastic limit: $\%$ & Liquid limit: $\%$ & Plasticity index & $S_{\mathrm{u}}$ : kPa & Residual $\phi^{\prime}:$ degrees \\
\hline Oxford clay & $24-27$ & $32-35$ & $64-67$ & $30-34$ & $200-300$ & 10 \\
Kimmeridge clay & $16-21$ & $18-22$ & $46-55$ & $28-33$ & $80-100$ & 7 \\
Gault clay & $28-30$ & $28-31$ & $71-77$ & $40-46$ & $70-90$ & 10 \\
London clay (Unit B2c) & $23-25$ & $26-27$ & $68-70$ & $41-44$ & $120-170$ & 12 \\
\hline
\end{tabular}
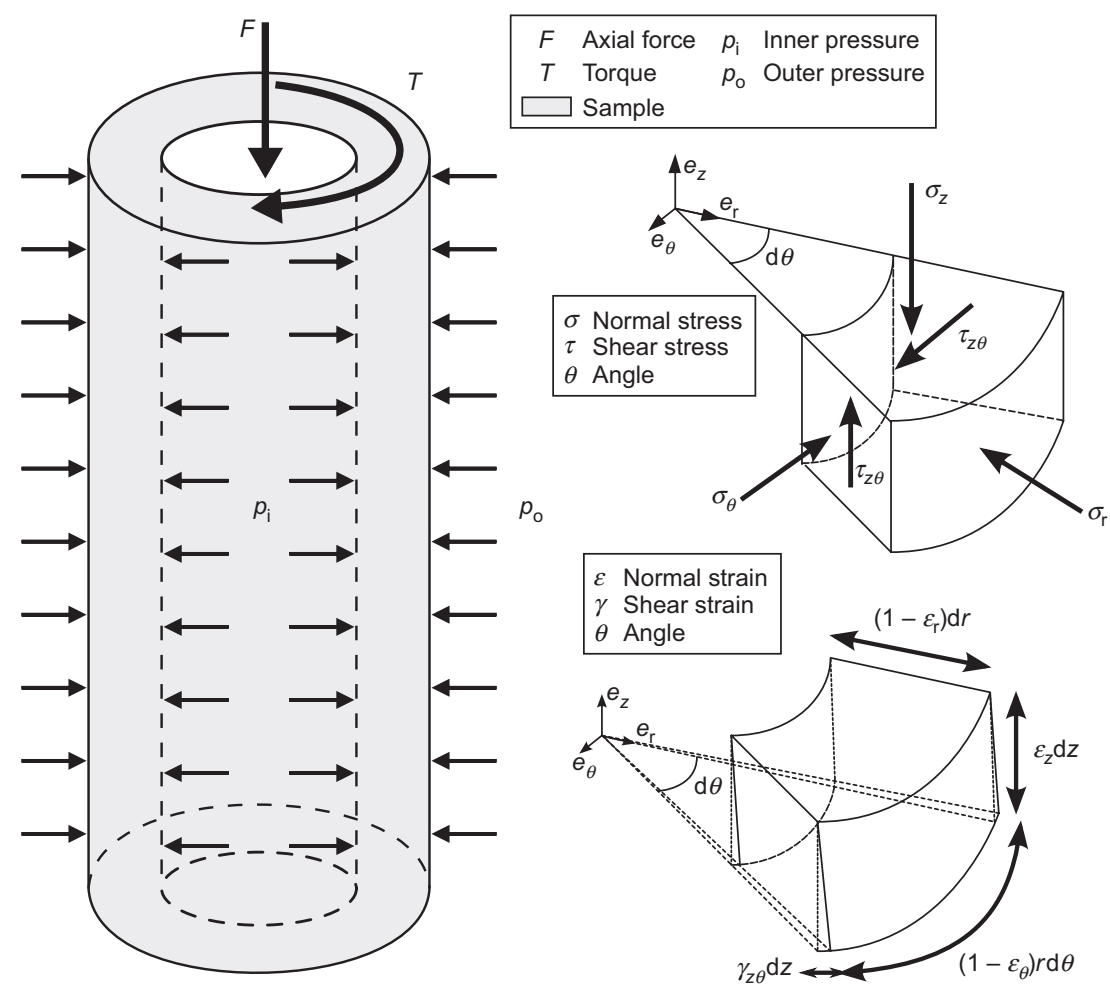

Fig. 3. Schematic diagram of the stress and strain states imposed in a hollow cylinder sample

Table 3. Average stresses and strains obtained from boundary measurements in an HCA; after Hight et al. (1983)

\begin{tabular}{|c|c|c|}
\hline & Stresses & Strains \\
\hline Vertical & $\sigma_{z}=\frac{F}{\pi\left(r_{\mathrm{o}}^{2}-r_{\mathrm{i}}^{2}\right)}+\frac{p_{\mathrm{o}} r_{\mathrm{o}}^{2}-p_{\mathrm{i}} r_{\mathrm{i}}^{2}}{r_{\mathrm{o}}^{2}-r_{\mathrm{i}}^{2}}$ & $\varepsilon_{z}=-\frac{\Delta H}{H}$ \\
\hline Radial & $\sigma_{\mathrm{r}}=\frac{p_{\mathrm{o}} r_{\mathrm{o}}+p_{\mathrm{i}} r_{\mathrm{i}}}{r_{\mathrm{o}}+r_{\mathrm{i}}}$ & $\varepsilon_{\mathrm{r}}=-\frac{\Delta r_{\mathrm{o}}-\Delta r_{\mathrm{i}}}{r_{\mathrm{o}}-r_{\mathrm{i}}}$ \\
\hline Circumferential & $\sigma_{\theta}=\frac{p_{\mathrm{o}} r_{\mathrm{o}}-p_{\mathrm{i}} r_{\mathrm{i}}}{r_{\mathrm{o}}-r_{\mathrm{i}}}$ & $\varepsilon_{\theta}=-\frac{\Delta r_{\mathrm{o}}+\Delta r_{\mathrm{i}}}{r_{\mathrm{o}}+r_{\mathrm{i}}}$ \\
\hline Shear & $\tau_{z \theta}=\frac{3 T}{2 \pi\left(r_{\mathrm{o}}^{3}-r_{\mathrm{i}}^{3}\right)}$ & $\gamma_{z \theta}=\frac{2 \Delta \theta\left(r_{\mathrm{o}}^{3}-r_{\mathrm{i}}^{3}\right)}{3 H\left(r_{\mathrm{o}}^{2}-r_{\mathrm{i}}^{2}\right)}$ \\
\hline Major principal & $\sigma_{1}=\frac{\sigma_{z}+\sigma_{\theta}}{2}+\sqrt{\left(\frac{\sigma_{z}-\sigma_{\theta}}{2}\right)^{2}+\left(\tau_{z \theta}\right)^{2}}$ & $\varepsilon_{1}=\frac{\varepsilon_{z}+\varepsilon_{\theta}}{2}+\sqrt{\left(\frac{\varepsilon_{z}-\varepsilon_{\theta}}{2}\right)^{2}+\left(\frac{\gamma_{z \theta}}{2}\right)^{2}}$ \\
\hline Intermediate principal & $\sigma_{2}=\sigma_{\mathrm{r}}$ & $\varepsilon_{2}=\varepsilon_{\mathrm{r}}$ \\
\hline Minor principal & $\sigma_{3}=\frac{\sigma_{z}+\sigma_{\theta}}{2}-\sqrt{\left(\frac{\sigma_{z}-\sigma_{\theta}}{2}\right)^{2}+\left(\tau_{z \theta}\right)^{2}}$ & $\varepsilon_{3}=\frac{\varepsilon_{z}+\varepsilon_{\theta}}{2}-\sqrt{\left(\frac{\varepsilon_{z}-\varepsilon_{\theta}}{2}\right)^{2}+\left(\frac{\gamma_{z \theta}}{2}\right)^{2}}$ \\
\hline
\end{tabular}

$H$, specimen height; $r_{\mathrm{i}}$ and $r_{\mathrm{o}}$, inner and outer radii; $F$, forces measured by the load cell placed beneath the specimen, minus half the specimen's submerged weight; $\Delta \theta=$ relative torsional angle between the specimen top and bottom. The other variables are defined in Fig. 3 .

measurements. The average strains reported for individual test stages were calculated with respect to the specimen dimensions applying at the beginning of that stage. Careful calibration of the employed pressure and force transducers against precise comparators over adequate ranges resulted in measurements of stresses with accuracies between 0.5 and $4.0 \mathrm{kPa}$ (and far finer resolutions), depending on the individual sensors deployed. The displacement measuring 


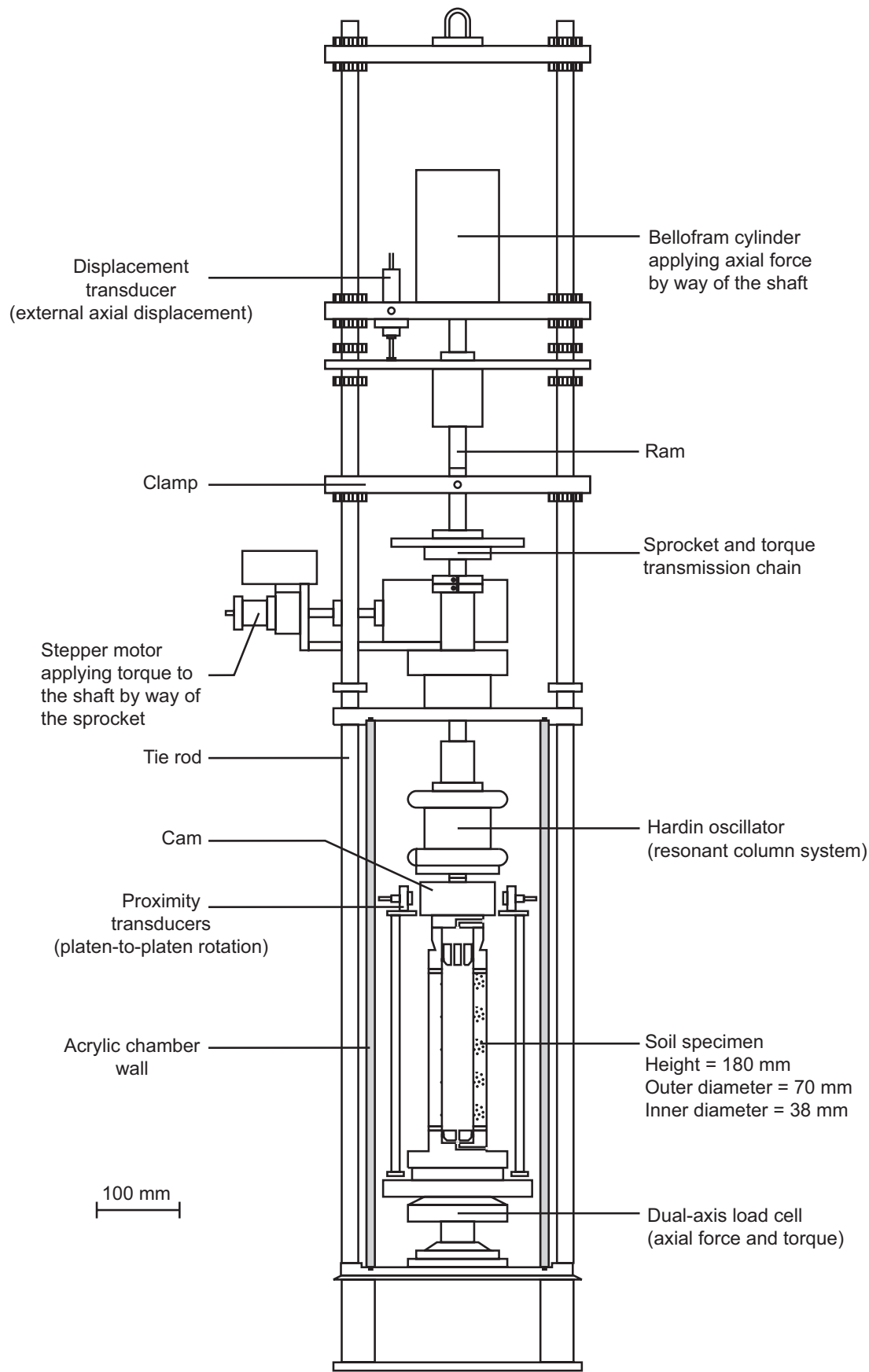

Fig. 4. Schematic diagram of the Imperial College Resonant column hollow cylinder apparatus (ICRCHCA) (Nishimura, 2006; Brosse, 2012)

system calibrations allowed measurement of strains with accuracies in the order of $10^{-4}$ or finer.

\section{Specimen preparation}

The HCA specimens were prepared by trimming cylinders to the specified outer dimensions with a wire saw in a rotary soil lathe. The inner cylinder void was then formed by jacketing the sample in an aluminium mould and using a metal working lathe to advance six drill bits of gradually increasing diameters to achieve the desired inner diameter with minimal disturbance. The specimens were carefully installed with both internal and external latex membranes and systems of surface filter paper drains in place, and were set on the edges of shear vanes anchored into the HCAs' sintered bronze vertical platens. The latter ensured that sufficient traction could be applied during torsional shearing to failure.

\section{Test programme}

Figure 6 illustrates the general scheme of the stress paths applied in the undrained HCA tests. The influences of $b$ and $\alpha$ were studied independently in the London clay HCA experiments by Nishimura (2006) and Anh Minh (2006), who investigated a wide range of depths at their single test site. Nishimura (2006) and Brosse (2007) also performed undrained HCA simple shear tests on London clay specimens from a range of depths and, at one depth, at a spread of effective stress levels; Nishimura et al. (2008) report a summary of the results. Brosse's (2012) work covered three different sites and clays, Oxford, Kimmeridge and Gault, focusing on a narrow depth range and on the effect of $\alpha$ by maintaining $b=0.5$ in all the 'stress-path' tests. Undrained HCA simple shear tests were also undertaken on each clay.

This paper reports 32 successful HCA tests, each of which took around one month to complete. Tables 4-7 specify each 


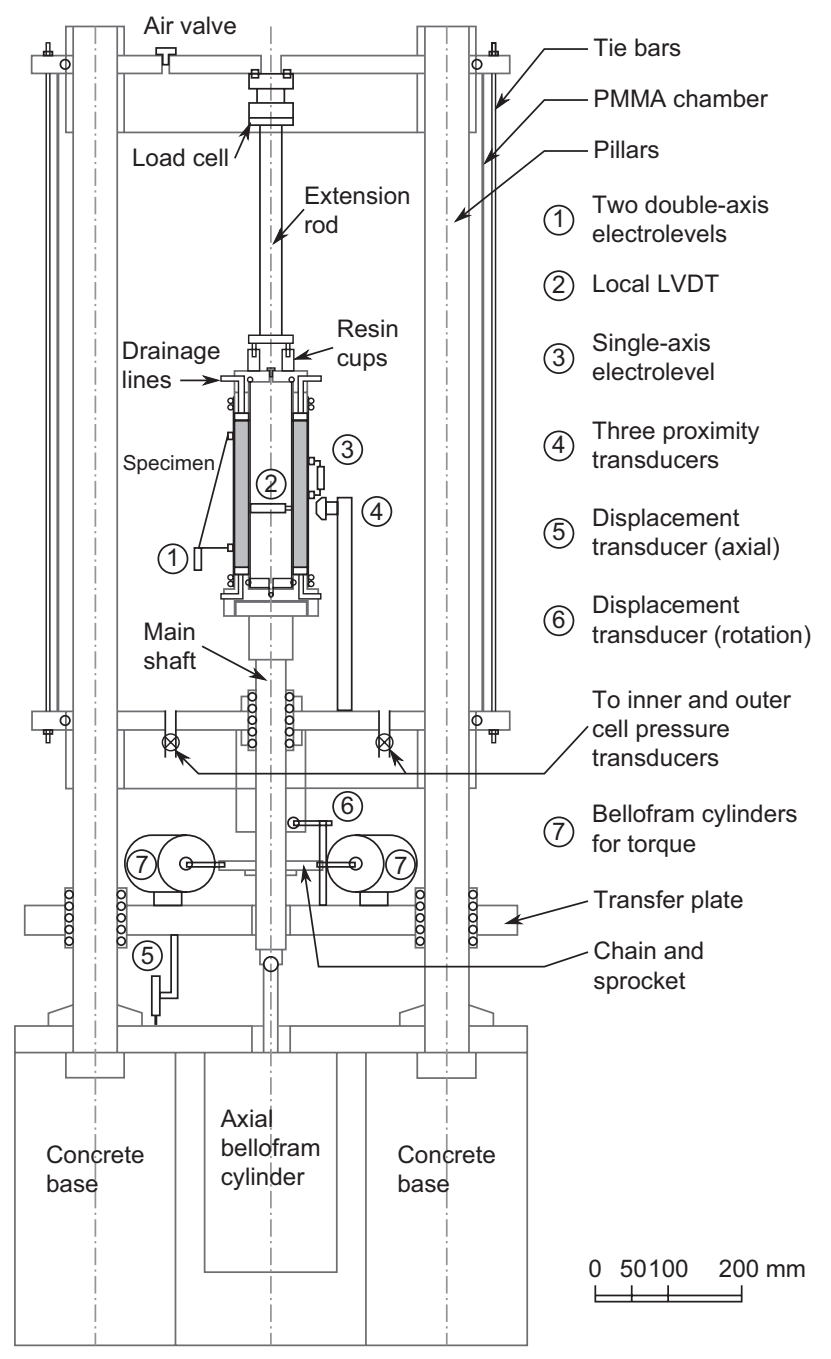

Fig. 5. Schematic diagram of the Imperial College hollow cylinder apparatus mark II (ICHCA II) (modified after Nishimura et al. (2007)) (PMMA, poly(methyl methacrylate)) test's code, sampling depth, reconsolidation effective stresses and shearing effective stress path. The tabulated Gault, Kimmeridge and Oxford clay sites were all free from any other type of overburden. However, the London Clay at Heathrow at T5 had been overlain by $6 \mathrm{~m}$ of Quaternary Thames River Terrace gravels that had been removed at the block sampling location some 70 years before sampling, but was still present at the rotary coring site. The reported London clay block specimens were taken at $\approx 10 \mathrm{~m}$ depth, while the rotary samples from the same unit were retrieved from $16 \mathrm{~m}$ below current ground level. To maintain compatibility, both types of specimen were tested at the same effective stress levels, which represent those applying currently at the rotary coring site and 70 years earlier at the block sampling location. The London clay specimens were therefore tested from higher effective stresses than the three other clays. The implications and importance of reproducing the in situ effective stress levels in the tests in assessing the strength anisotropy are discussed later.

\section{Test procedures}

All tests started by applying a cell pressure greater than the estimated in situ mean effective stress to induce a positive pore pressure once full contact was made between the sample and the platens. Saturation stages ensued, in which back pressures were increased to attain acceptable initial undrained pore pressure response ratios. It can be hard to obtain high $B$ values with the high bulk stiffness $\left(K^{\prime}>100 \mathrm{MPa}\right)$ clays tested, but initial $B$ values exceeding 0.9 were obtained in most of the specimens reported and only marginally lower ratios in a few cases. Subsequently, all specimens were reconsolidated under high back pressures $(200-400 \mathrm{kPa})$ to effective stress states reflecting those estimated in situ and further saturation took place over these extended test stages. All but four of the specimens considered in this paper were reconsolidated to anisotropic stress conditions.

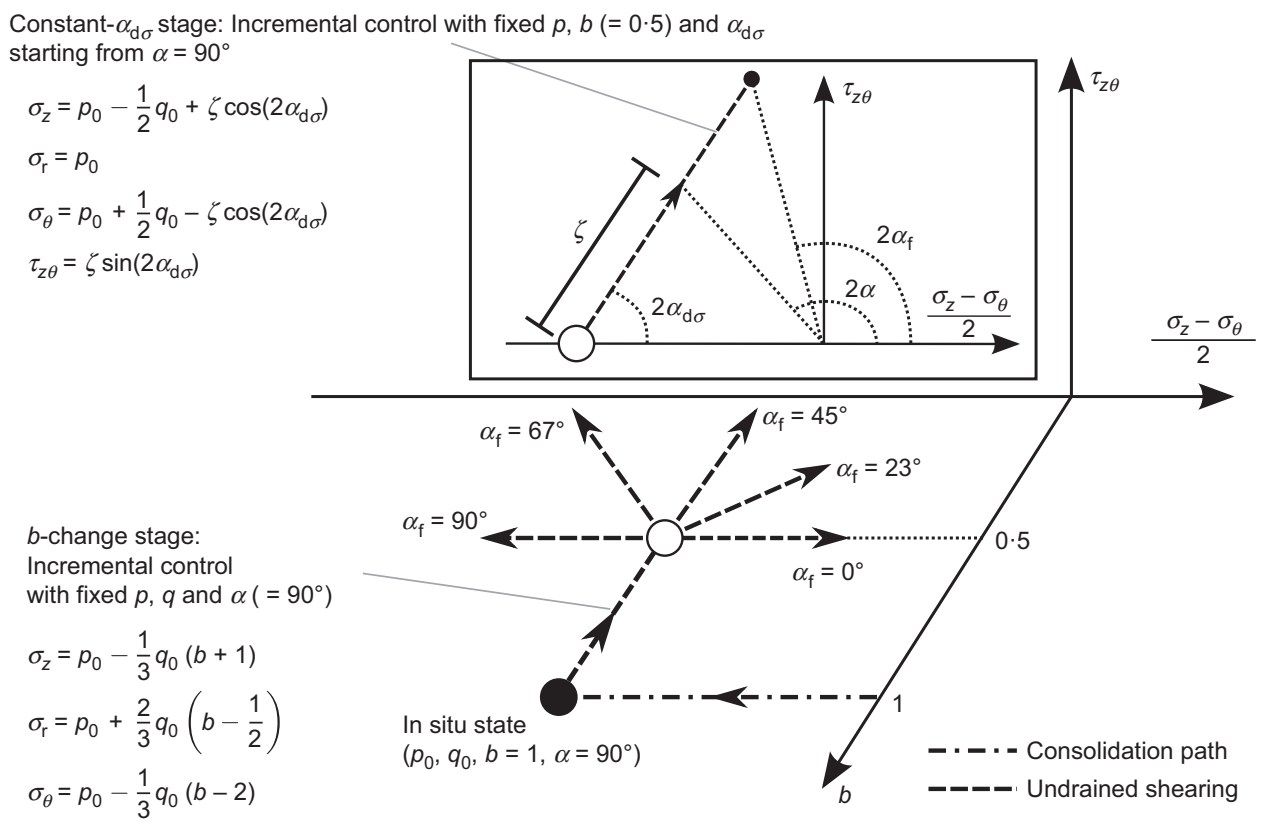

Fig. 6. Schematic diagram of the undrained stress paths followed during shearing at constant- $\alpha_{\mathrm{d} \sigma}$ from in situ stresses in the HCA test series 
Table 4. Summary of HCA tests for Oxford clay series

\begin{tabular}{|c|c|c|c|c|c|c|c|c|c|c|}
\hline \multirow{2}{*}{$\begin{array}{l}\text { Test } \\
\text { reference }\end{array}$} & \multirow{2}{*}{$\begin{array}{l}\text { Sample } \\
\text { type }\end{array}$} & \multirow{2}{*}{$\begin{array}{c}\text { Specimen } \\
\text { depth: } m B G L\end{array}$} & \multirow[t]{2}{*}{ Type of test } & \multicolumn{2}{|c|}{ Initial stresses } & \multirow{2}{*}{$\begin{array}{c}\alpha_{\mathrm{d} \sigma}: \\
\text { degrees }\end{array}$} & \multirow[t]{2}{*}{$b \dagger$} & \multicolumn{3}{|c|}{ Stress state at peak $q$} \\
\hline & & & & $p_{0}^{\prime}: \mathrm{kPa}$ & $\sigma_{\mathrm{v} 0}^{\prime}-\sigma_{\mathrm{h} 0}^{\prime}: \mathrm{kPa}$ & & & $p_{\mathrm{f}}^{\prime}: \mathrm{kPa}$ & $q_{\mathrm{f}}: \mathrm{kPa}$ & $\alpha_{\mathrm{f}}:$ degrees \\
\hline OA0005 & Block & 10 & Constant $\alpha_{\mathrm{d} \sigma}$ & 250 & -130 & 0 & $0 \cdot 5$ & 202 & 350 & 0 \\
\hline OA2305 & Block & 10 & Constant $\alpha_{\mathrm{d} \sigma}$ & 250 & -130 & 15 & $0 \cdot 5$ & 151 & 290 & 22 \\
\hline OA4505 & Block & 10 & Constant $\alpha_{\mathrm{d} \sigma}$ & 252 & -125 & 30 & $0 \cdot 5$ & 213 & 255 & 43 \\
\hline OA6705 & Block & 10 & Constant $\alpha_{\mathrm{d} \sigma}$ & 250 & -130 & 57 & $0 \cdot 5$ & 250 & 290 & 69 \\
\hline OA9005 & Block & 10 & Constant $\alpha_{\mathrm{d} \sigma}$ & 252 & -125 & 90 & $0 \cdot 5$ & 371 & 520 & 90 \\
\hline $\mathrm{OA} 0005^{*}+$ & Block & 10 & Constant $\alpha_{\mathrm{d} \sigma}$ & 252 & -125 & 0 & $0 \cdot 5$ & 203 & 318 & 0 \\
\hline OASS & Block & 10 & Simple shear & 250 & -130 & - & 0.58 & 218 & 224 & 57 \\
\hline
\end{tabular}

All tests were performed in the ICRCHCA apparatus.

$\dagger$ For simple shear tests the $b$ value at peak $q$ is given.

$\$$ Test OA0005* reproduced OA0005 conditions with a different specimen.

Table 5. Summary of HCA tests for Kimmeridge clay series

\begin{tabular}{|c|c|c|c|c|c|c|c|c|c|c|}
\hline \multirow{2}{*}{$\begin{array}{l}\text { Test } \\
\text { reference }\end{array}$} & \multirow{2}{*}{$\begin{array}{l}\text { Sample } \\
\text { type }\end{array}$} & \multirow{2}{*}{$\begin{array}{c}\text { Specimen } \\
\text { depth: } \\
\text { mBGL }\end{array}$} & \multirow[t]{2}{*}{ Type of test } & \multicolumn{2}{|c|}{ Initial stresses } & \multirow{2}{*}{$\begin{array}{c}\alpha_{\mathrm{d} \sigma}: \\
\text { degrees }\end{array}$} & \multirow[t]{2}{*}{$b^{*}$} & \multicolumn{3}{|c|}{ Stress state at peak $q$} \\
\hline & & & & $p_{0}^{\prime}: \mathrm{kPa}$ & $\sigma_{\mathrm{v} 0}^{\prime}-\sigma_{\mathrm{h} 0}^{\prime}: \mathrm{kPa}$ & & & $p_{\mathrm{f}}^{\prime}: \mathrm{kPa}$ & $q_{\mathrm{f}}: \mathrm{kPa}$ & $\alpha_{\mathrm{f}}:$ degrees \\
\hline KA0005 & Rotary core & $11 \cdot 4$ & Constant $\alpha_{\mathrm{d} \sigma}$ & 186 & -97 & 0 & $0 \cdot 5$ & 172 & 199 & 0 \\
\hline KA2305 & Rotary core & $11 \cdot 2$ & Constant $\alpha_{\mathrm{d} \sigma}$ & 186 & -97 & 14 & $0 \cdot 5$ & 166 & 195 & 21 \\
\hline KA4505 & Rotary core & $11 \cdot 5$ & Constant $\alpha_{\mathrm{d} \sigma}$ & 186 & -97 & 30 & $0 \cdot 5$ & 200 & 252 & 40 \\
\hline KA6705 & Rotary core & $11 \cdot 9$ & Constant $\alpha_{\mathrm{d} \sigma}$ & 186 & -97 & 55 & $0 \cdot 5$ & 248 & 323 & 63 \\
\hline KA9005 & Rotary core & $11 \cdot 7$ & Constant $\alpha_{\mathrm{d} \sigma}$ & 186 & -97 & 90 & $0 \cdot 5$ & 278 & 350 & 90 \\
\hline KASS & Rotary core & $9 \cdot 0$ & Simple shear & 186 & -97 & - & $0 \cdot 43$ & 231 & 302 & 53 \\
\hline
\end{tabular}

Constant $-\alpha_{\mathrm{d} \sigma}$ tests were performed in the ICHCA II and the simple shear test in the ICRCHCA.

*For simple shear tests the $b$ value at peak $q$ is given.

Table 6. Summary of HCA tests for Gault clay series

\begin{tabular}{|c|c|c|c|c|c|c|c|c|c|c|}
\hline \multirow{2}{*}{$\begin{array}{l}\text { Test } \\
\text { reference }\end{array}$} & \multirow{2}{*}{$\begin{array}{l}\text { Sample } \\
\text { type }\end{array}$} & \multirow{2}{*}{$\begin{array}{l}\text { Specimen } \\
\text { depth: } \\
\text { mBGL }\end{array}$} & \multirow[t]{2}{*}{ Type of test } & \multicolumn{2}{|c|}{ Initial stresses } & \multirow[t]{2}{*}{$\alpha_{\mathrm{d} \sigma}:$ degrees } & \multirow[t]{2}{*}{$b \dagger$} & \multicolumn{3}{|c|}{ Stress state at peak $q$} \\
\hline & & & & $p_{0}^{\prime}: \mathrm{kPa}$ & $\sigma_{\mathrm{v} 0}^{\prime}-\sigma_{\mathrm{h} 0}^{\prime}: \mathrm{kPa}$ & & & $p_{\mathrm{f}}^{\prime}: \mathrm{kPa}$ & $q_{\mathrm{f}}: \mathrm{kPa}$ & $\alpha_{\mathrm{f}}:$ degrees \\
\hline GA0005 & Rotary core & $9 \cdot 5$ & Constant $\alpha_{\mathrm{d} \sigma}$ & 163 & -85 & 0 & $0 \cdot 5$ & 146 & 212 & 0 \\
\hline GA2305 & Rotary core & $9 \cdot 8$ & Constant $\alpha_{\mathrm{d} \sigma}$ & 163 & -85 & 15 & $0 \cdot 5$ & 163 & 207 & 21 \\
\hline GA4505 & Rotary core & $11 \cdot 8$ & Constant $\alpha_{\mathrm{d} \sigma}$ & 163 & -85 & 28 & 0.5 & 157 & 189 & 39 \\
\hline GA6705 & Rotary core & $10 \cdot 6$ & Constant $\alpha_{\mathrm{d} \sigma}$ & 163 & -85 & 55 & $0 \cdot 5$ & 200 & 224 & 65 \\
\hline GA9005 & Rotary core & $10 \cdot 3$ & Constant $\alpha_{\mathrm{d}}$ & 163 & -85 & 90 & 0.5 & 206 & 252 & 90 \\
\hline GA2305* & Rotary core & $12 \cdot 5$ & Constant $\alpha_{\mathrm{d} \sigma}$ & 163 & -85 & 15 & 0.5 & $\underline{200}$ & - & - \\
\hline GASS & Rotary core & $10 \cdot 9$ & Simple shear & 163 & -85 & - & $0 \cdot 45$ & 162 & 198 & 53 \\
\hline
\end{tabular}

All tests were performed in the ICRCHCA apparatus.

$\dagger$ For simple shear tests the $b$ value at peak $q$ is given.

$\$$ Test GA2305* was interrupted during shearing due to a power outage. Data are presented up to that point.

Table 7. Summary of HCA tests for London clay series

\begin{tabular}{|c|c|c|c|c|c|c|c|c|c|c|}
\hline \multirow{2}{*}{$\begin{array}{l}\text { Test } \\
\text { reference }\end{array}$} & \multirow{2}{*}{$\begin{array}{l}\text { Sample } \\
\text { type }\end{array}$} & \multirow{2}{*}{$\begin{array}{c}\text { Specimen } \\
\text { depth†: } \\
\text { mBGL }\end{array}$} & \multirow[t]{2}{*}{ Type of test } & \multicolumn{2}{|c|}{ Initial stresses } & \multirow[t]{2}{*}{$\alpha_{\mathrm{d} \sigma}:$ degrees } & \multirow[t]{2}{*}{$b^{*}$} & \multicolumn{3}{|c|}{ Stress state at peak $q$} \\
\hline & & & & $p_{0}^{\prime}: \mathrm{kPa}$ & $\sigma_{\mathrm{v} 0}^{\prime}-\sigma_{\mathrm{h} 0}^{\prime}: \mathrm{kPa}$ & & & $p_{\mathrm{f}}^{\prime}: \mathrm{kPa}$ & $q_{\mathrm{f}}: \mathrm{kPa}$ & $\alpha_{\mathrm{f}}:$ degrees \\
\hline LA0005 & Block & $16 \cdot 3$ & Constant $\alpha_{\mathrm{d} \sigma}$ & 323 & -165 & 0 & $0 \cdot 5$ & 282 & 318 & 0 \\
\hline LA2305 & Block & $16 \cdot 3$ & Constant $\alpha_{\mathrm{d} \sigma}$ & 323 & -165 & 15 & $0 \cdot 5$ & 296 & 303 & 23 \\
\hline LA4505 & Block & $16 \cdot 3$ & Constant $\alpha_{\mathrm{d} \sigma}$ & 323 & -165 & 30 & $0 \cdot 5$ & 302 & 242 & 48 \\
\hline LA6705 & Block & $16 \cdot 3$ & Constant $\alpha_{\mathrm{d} \sigma}$ & 323 & -165 & 55 & $0 \cdot 5$ & 365 & 381 & 67 \\
\hline LA9005 & Block & $16 \cdot 3$ & Constant $\alpha_{\mathrm{d} \sigma}$ & 323 & -165 & 90 & $0 \cdot 5$ & 415 & 484 & 90 \\
\hline LASS & Rotary core & $16 \cdot 2$ & Simple shear & 315 & -171 & - & $0 \cdot 56$ & 301 & 245 & 53 \\
\hline LASS1 & Rotary core & $15 \cdot 8$ & Simple shear & 252 & -120 & - & $0 \cdot 42$ & 314 & 323 & 48 \\
\hline LASS2 & Block & $16 \cdot 3$ & Simple shear & 323 & -165 & - & $0 \cdot 64$ & 317 & 277 & 53 \\
\hline LISS & Rotary core & $15 \cdot 6$ & Simple shear & 285 & 0 & - & $0 \cdot 51$ & 322 & 278 & 51 \\
\hline LISS1 & Block & $16 \cdot 3$ & Simple shear & 50 & 0 & - & $0 \cdot 44$ & 79 & 96 & 54 \\
\hline LISS2 & Block & $16 \cdot 3$ & Simple shear & 150 & 0 & - & $0 \cdot 48$ & 207 & 202 & 51 \\
\hline LISS3 & Rotary core & 15 & Simple shear & 450 & 0 & - & $0 \cdot 47$ & 438 & 359 & 48 \\
\hline
\end{tabular}

All tests were performed in the ICRCHCA apparatus.

*For simple shear tests the $b$ value at peak $q$ is given.

$\dagger$ For block samples, the indicated depth includes $5.8 \mathrm{~m}$ of Thames River Terrace gravel that had been removed 70 years before sampling (see Nishimura et al., 2007). 
Estimating in situ $K_{0}$ is not straightforward in these heavily overconsolidated clays. Three approaches were followed in initial scoping tests, as described below.

(a) Equation (6), proposed by Mayne \& Kulhawy (1982), was evaluated after assessing the in situ OCRs of the four clays. However, this approach was hampered by uncertainties in the maximum burial depths and in the effects of recent stress history, including glaciation and tree action.

$$
K_{0}=\left(1-\sin \phi^{\prime}\right) \mathrm{OCR}^{\sin \phi^{\prime}}
$$

(b) $K_{0}$ values were interpreted from suction measurements made on multiple triaxial and HCA samples, making allowance for deviator stress release and carefully establishing the in situ vertical effective stress.

(c) In situ measurements were considered that had been made with a Marchetti dilatometer in the Kimmeridge clay and a self-boring pressuremeters for the Oxford clay.

The $K_{0}$ ranges estimated from these above sources are listed in Table 1. In selecting the finally chosen test values (see Table 1), it was noted that several estimates exceeded the theoretical lower bound passive coefficient $K_{\mathrm{p}} \approx 2$ as evaluated with triaxial compression $\phi^{\prime}$ values obtained from either optimally fissured natural samples, or the critical state angles from tests on reconstituted samples (Hosseini Kamal et al., 2014). It was also noted that trying to apply $K>2$ led to excessive shear straining during reconsolidation of the first clay tested in Brosse's (2012) study, Oxford clay. As a result, Oxford clay samples were tested from $K=1.8$ instead of the estimated values of $3 \cdot 2$, so that the shear stage started from higher vertical stresses than in situ for this soil (see Tables 1 and 4). Uniform $K$ values of 1.8 were therefore adopted for the remaining Gault and Kimmeridge clays that represented consistent best estimates and simplified test interpretation with the earlier London clay LA series, which adopted the same $K_{0}$ value $(=1 \cdot 8)$.

Drained isotropic reconsolidation was conducted first to reach the desired $p^{\prime}$ values and then $\left(\sigma_{z}-\sigma_{\theta}\right) / 2$ was reduced, keeping constant $p^{\prime}$, to reach the estimated in situ effective stress conditions. Small-strain non-destructive resonant column tests were conducted during all ICRCHCA tests to monitor how $G_{z \theta}$ varied during reconsolidation and shearing; see Gasparre et al. (2007b) and Brosse et al. (2016, 2017). The latter had no discernible effect on permanent strains or pore water pressures and so did not affect the subsequent strength measurements.

Stress-strain measurements can be severely compromised by any residual creep straining that may apply prior to shearing; see Jardine (1985), Gasparre et al. (2014) or Nishimura (2014). Sufficient pause times were therefore imposed after all consolidation stages for creep rates to stabilise before commencing undrained shearing. Several days were required for the axial strain rates to fall below the adopted $0 \cdot 002 \% / \mathrm{h}$ criterion.

The shearing stages of the experiments termed 'stress-path' or 'constant- $\alpha_{\mathrm{d} \sigma}$ ' tests all involved an intermediate stage to change $b$ from its initial value of unity (which applies with $K_{0}>1$ ) to the desired test value under undrained conditions, while keeping $p, q$ and $\alpha$ constant. Nishimura et al. (2007) explored a wide range of $b$ values in experiments on London clay, but only $\alpha_{\mathrm{d} \sigma}$ tests involving $b=0.5$ are considered here. After allowing $12 \mathrm{~h}$ for creep, the final undrained shearing was initiated with constant $p, b$ and $\alpha_{\mathrm{d} \sigma}$ values, where $\alpha_{\mathrm{d} \sigma}$ is the direction of the axis of the major principal stress increment, as defined by equation (4). This 'tangent' expression refers to the angles developed over small increments of stress change. However, the $\alpha_{\mathrm{d} \sigma}$ directions were kept constant during the shearing stages of all tests, except the simple shear experiments in which the samples' vertical and circumferential stresses were able to respond spontaneously to the imposed kinematic control conditions of zero vertical, radial and circumferential strains. With the exception of the experiments imposing $\alpha_{\mathrm{d} \sigma}=0^{\circ}$ and $90^{\circ}$, tests that started from $K>1$ experienced continuous variations in $\alpha$ during undrained shearing, as illustrated in Fig. 6 . The imposed values of $\alpha_{\mathrm{d} \sigma}$ were selected so that for each test peak $q$ developed at $\alpha$ values close to targets of $0^{\circ}, 23^{\circ}, 45^{\circ}, 67^{\circ}$ and $90^{\circ}$. The latter were achieved accurately, as demonstrated in Tables $4-7$ by the peak $q$ angles, which are denoted as $\alpha_{\mathrm{f}}$. The shearing stages of the constant- $\alpha_{\mathrm{d} \sigma}$ tests were conducted under a mixed stress and strain control arrangement to obtain a constant average deviatoric strain rate of $0 \cdot 15 \% / \mathrm{h}$ (Brosse, 2012). Future investigations may be able to consider whether strain rate has any effect on shear strength anisotropy. In experiments applying $23^{\circ}<\alpha_{\mathrm{d} \sigma}<67^{\circ}$ the torsional loading was driven at a constant rate, while the axial load and cell pressures were controlled to keep the prescribed stress path. For the $0^{\circ}$ and $90^{\circ}$ conditions the axial displacement was driven at a constant rate, and the cell pressures controlled to follow the desired stress path. The driving rates of the 'principal' loading devices were adjusted after trial experiments to achieve the target deviatoric strain rate. Examples are shown in Fig. 7 of how each stress component was varied (following the equations presented in Fig. 6) during the $b$-change and $q$-change stages of test OA6705.

The HCA simple shear tests were set up and reconsolidated in the same way as the 'stress-path' tests. No $b$-change stage was included. Instead, spontaneous $b$ changes were observed as part of the specimens' response to the imposed simple shearing conditions. Most involved $K_{0}$ reconsolidation to in situ stresses except for Brosse's (2007) 'variable stress' London clay tests, which were swelled/consolidated to a range of $p^{\prime}$ and shear from isotropic conditions. The experiments progressed directly from their equilibrium reconsolidated states to undergo undrained torsional shear straining at $0 \cdot 15 \% / \mathrm{h}$. The specimen heights and inner cavity volumes were kept constant by mechanical constraints (closing the drainage valves and restricting the axial shaft displacements). The outer cell pressure was constant and a servo system controlled the axial force to compensate for any effects of apparatus compliance. As described by Nishimura (2006), Minh et al. (2011) and Brosse (2012) this arrangement overcame the considerable boundary condition difficulties, non-uniformities, sample size effects and uncertainties implicit in conventional simple shear testing and led to results that could be expressed fully in terms of the four-dimensional stress and strain tensors, along with direct measurements of the samples' pore water pressure responses. The simple shear tests typically failed with $50^{\circ}<\alpha<60^{\circ}$ and $b$ between $0 \cdot 4$ and $0 \cdot 6$.

\section{Stress and strain measurements}

Accurate measurement, from the very early stages up to failure, of the four-dimensional stress and strain states developed in HCA tests poses considerable technical difficulties. The HCA cells illustrated in Figs 4 and 5 were set in a tightly temperature-regulated laboratory. Very stable, 16-bit resolution auto-ranging analogue-to-digital converters were employed to track the stress and strain measurements. Both HCA systems employed high-quality inner and outer cell pressure measurements as well as purpose-designed, dual-axis, pressure-compensated, internal load cells that measured the axial force and torque applied to the samples. 
These biaxial cells were carefully calibrated for both direct and cross-sensitivity under the load paths applied employed for testing. As described above, the two HCA sets employed a mix of local or semi-local (platen-to-platen) strain measurements in conjunction with global measurements of the axial displacement and volume changes. Apparatus compliance effects were alleviated in the ICRHCA by making

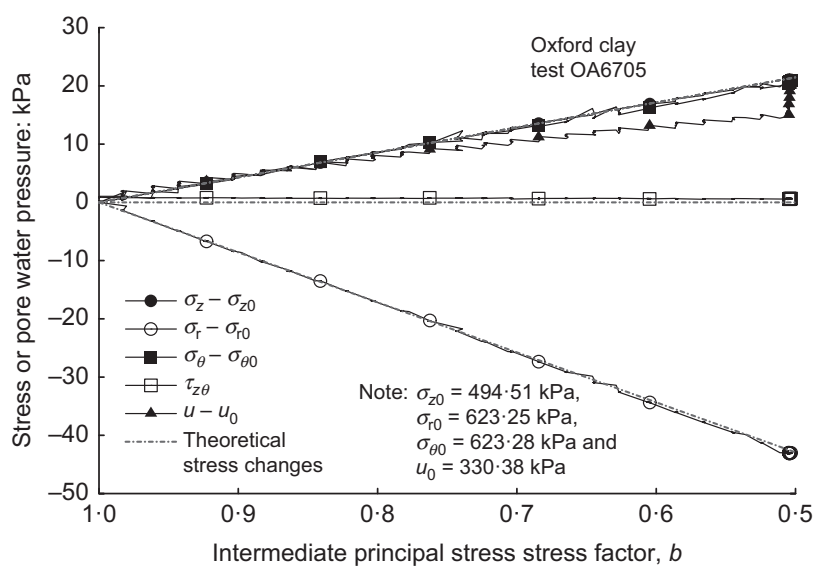

(a)

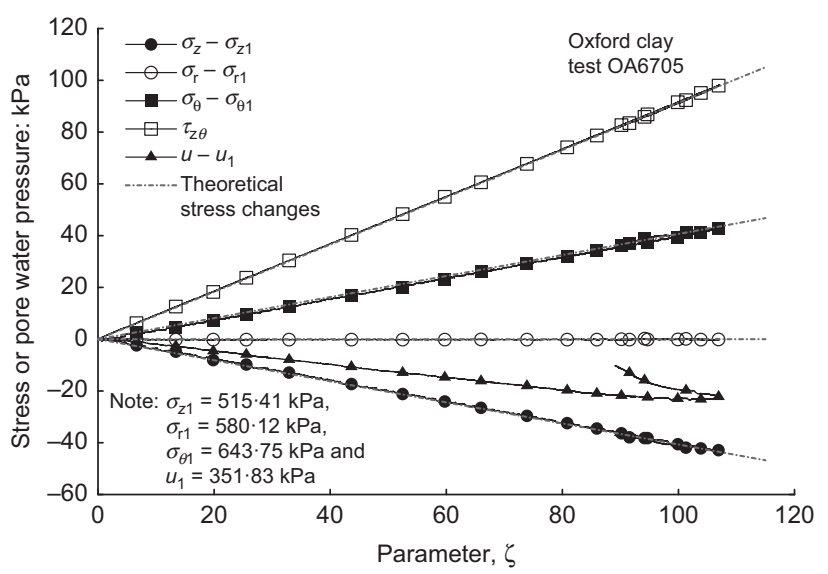

(b)

Fig. 7. Example of stress control showing theoretical and measured values during (a) $b$-change and (b) constant- $\alpha_{\mathrm{d} \sigma}$ stages in test OA6705. For ease of reading, only the stress changes from the beginning of each stage are plotted. Initial stress states for each stage are indicated on the respective figures platen-to-platen torsional shear strain measurements and applying calibrated compliance corrections to external axial strain measurements, while the rigid HCA connection systems reduced any loading eccentricity or tilting. Full local strain instrumentation was deployed in the ICHCA II experiments. Membrane penetration was not significant with the fine-grained clays tested. The sample platen contacts were made as effective as possible by using sintered bronze porous discs, shear vanes and consolidation stages that imposed pre-shearing vertical loads. The resolutions and accuracies of the various instruments are summarised in Table 8 . The electro-mechanical systems allowed precise controls of all the pressures $( \pm 0 \cdot 2 \mathrm{kPa})$ and the axial force $( \pm 0 \cdot 2 \mathrm{~N})$. These systems, along with fully automated feedback personal computer (PC) controls, permitted precise application of $p$ $( \pm 0.5 \mathrm{kPa}), q( \pm 1 \mathrm{kPa}), \alpha\left( \pm 0 \cdot 1^{\circ}\right.$; except at stresses very close to isotropic states, where $\alpha$ is indeterminate) and $b( \pm 0 \cdot 005)$, even over test stages that extended for several hours.

\section{EXPERIMENTAL OUTCOMES}

The following sections outline general aspects of the shear strength and deformation characteristics observed in HCA tests on all four clays. Nishimura (2006), Nishimura et al. (2007, 2008) and Brosse (2012) provide numerous two-dimensional (2D) and three-dimensional (3D) plots to describe the effective stress paths and stress-strain relationships provided by the four degree of stress and strain freedom HCA experiments. This paper focuses on the sub-set of outcomes that are essential to characterise undrained shear strength anisotropy, while Brosse et al. (2016) describe the anisotropic and highly non-linear stiffness characteristics revealed by the HCA tests.

\section{Shear localisation}

Shear localisation had a vital impact on the clays' shearing behaviour. The onset of any shear localisation could be detected during HCA shearing by inspecting the deformation of a grid pattern drawn on the outer membrane and is designated as 'first rupture' herein. The optical magnification caused by the cell water allowed shear displacements of about $0.5 \mathrm{~mm}$ to be resolved by eye along any grid line, allowing shear band formation to be identified before the shear strain had grown by $0 \cdot 25 \%$ when continuous observations were made so that the $q$ value at first rupture could be estimated and identified on the stress-strain plots. Ranges are given for those cases where shear localisation started overnight.

Table 8. Resolution and accuracy of the instrumentation used in the ICRCHCA and ICHCA II

\begin{tabular}{|c|c|c|c|c|c|c|}
\hline \multirow[t]{2}{*}{ Parameters } & \multirow[t]{2}{*}{ Units } & \multirow[t]{2}{*}{ Location } & \multicolumn{2}{|c|}{ ICRCHCA } & \multicolumn{2}{|c|}{ ICHCA II } \\
\hline & & & Resolution & Accuracy* & Resolution & Accuracy* \\
\hline Axial force & $\mathrm{N}$ & External & $0 \cdot 004$ & $2 \cdot 02$ & $0 \cdot 007$ & $3 \cdot 76$ \\
\hline Torque & $\mathrm{N}$ m & External & $0 \cdot 0002$ & $0 \cdot 32$ & $0 \cdot 0005$ & $0 \cdot 69$ \\
\hline Pore water pressure & $\mathrm{kPa}$ & External & $0 \cdot 04$ & $0 \cdot 41$ & $0 \cdot 006$ & $0 \cdot 92$ \\
\hline Inner cell pressure & $\mathrm{kPa}$ & External & $0 \cdot 04$ & $0 \cdot 34$ & $0 \cdot 013$ & $0 \cdot 88$ \\
\hline Outer cell pressure & $\mathrm{kPa}$ & External & $0 \cdot 01$ & $1 \cdot 02$ & $0 \cdot 006$ & $0 \cdot 99$ \\
\hline Axial displacement & $\mathrm{mm}$ & External & $0 \cdot 0004$ & $0 \cdot 02$ & $0 \cdot 0005$ & $0 \cdot 01$ \\
\hline Sample volume change & $\mathrm{cm}^{3}$ & External & $0 \cdot 0008$ & $0 \cdot 04$ & $0 \cdot 0019$ & $0 \cdot 06$ \\
\hline Inner cell volume change & $\mathrm{cm}^{3}$ & External & $0 \cdot 0008$ & $0 \cdot 03$ & 0.0009 & $0 \cdot 08$ \\
\hline Rotation & degrees & External & $0 \cdot 0007$ & $0 \cdot 23$ & $0 \cdot 0005$ & $0 \cdot 02$ \\
\hline Outer wall displacement & $\mathrm{mm}$ & Internal & - & - & $0 \cdot 0004$ & $0 \cdot 0084$ \\
\hline Inner wall displacement & $\mathrm{mm}$ & Internal & - & - & $0 \cdot 0003$ & $0 \cdot 0018$ \\
\hline Axial displacement & $\mathrm{mm}$ & Internal & - & - & $0 \cdot 0004$ & $0 \cdot 011$ \\
\hline Shear strain & degrees & Internal & - & - & $0 \cdot 0002$ & $0 \cdot 041$ \\
\hline
\end{tabular}

*Accuracy is defined as the $95 \%$ confidence range (two standard deviations from the true value). 
Shear localisation and consequent strain non-uniformity is a well-recognised problem in soil testing, particularly with overconsolidated plastic clays such as those considered in this study. There is no perfect way to $(a)$ take account of their development and so $(b)$ deduce what might apply if the samples' response was perfectly uniform. Recognising this difficulty, the current authors report when shear localisation commenced in each test, as revealed by the grids marked on the specimens' external membranes and identify which parts of each test can be regarded as representing broadly continuous element behaviour and which parts represent the locally non-uniform global response. Two envelopes are therefore reported later in Figs 11, 12 and 15. Shear localisations can occur at microscales from the very early stages of shearing, as tomography by Viggiani \& Hall (2008) has shown. Any soil specimen, even if reconstituted, is inhomogeneous at some scale and it is usual to consider such 'non-uniform' aspects of behaviour as part of the element tests' overall response, provided that the specimens possess a sufficiently representative volume. Given the difficulties of characterising post-peak behaviour, the present authors offer no interpretation from the HCA tests of the clays' post-rupture, critical state or residual shear strengths. However, Hosseini Kamal et al. (2014) report how these aspects of behaviour were investigated in parallel triaxial and ring-shear experiments.

\section{Stress-strain behaviour}

This study involves experiments in which the stresses and strains have four degrees of freedom. The shear strengths developed can be expressed in a variety of ways. One approach is to adopt stress invariants to give a due consideration to all three principal stresses. However, in these particular test series with $b$ fixed at $0 \cdot 5$, the following simple relationships hold between commonly used parameters $p^{\prime}, s^{\prime}, q$ and $t$, and the first invariant $I_{1}$ of the Cauchy stress tensor and $J_{2}$ the second invariant of the deviatoric stress tensor

$$
\begin{aligned}
& p^{\prime}=\frac{I_{1}}{3} \\
& J=\sqrt{J_{2}}=\frac{1}{\sqrt{3}} \sqrt{1-b+b^{2}} q=\frac{q}{2}=t
\end{aligned}
$$

In the same way, when $b=0 \cdot 5$, the following relationship exists between the commonly used undrained shear strength, $S_{\mathrm{u}}$, and the generalised peak deviatoric stress, $J$

$$
S_{\mathrm{u}}=\frac{\sigma_{1}-\sigma_{3}}{2}=J_{\text {peak }}
$$

Therefore a peak of $q$ or $t$ coincides with that of $J$, and a peak of $t / s^{\prime}$ coincides with that of $J / p^{\prime}$. This paper adopts peak $S_{\mathrm{u}}$ and peak $t / s^{\prime}$ to quantify the shear strength, as these more widely employed measures of shear strength can be compared simply and directly with other types of experiment, such as triaxial tests.

The deviatoric stress-shear strain relationships, $q-\left(\varepsilon_{1}-\varepsilon_{3}\right)$, observed during the undrained shear stages of the suites

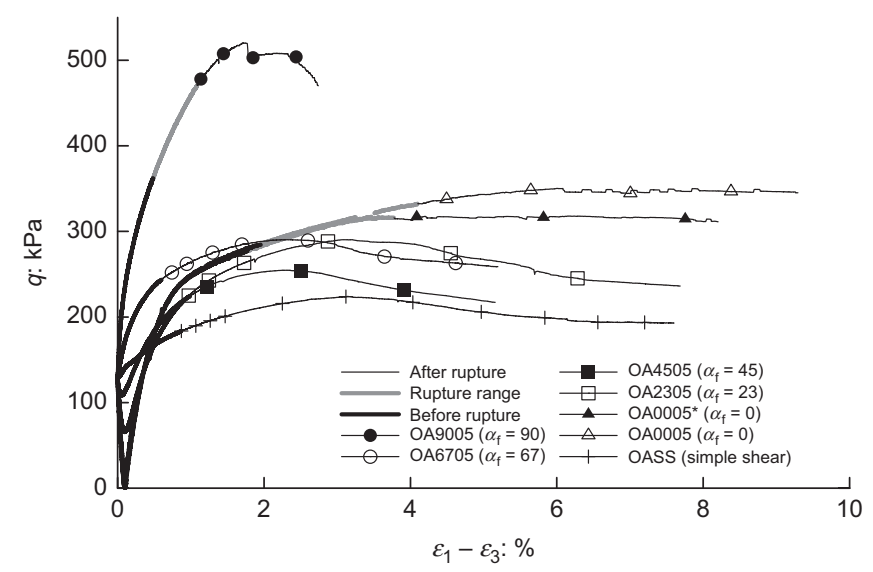

(a)

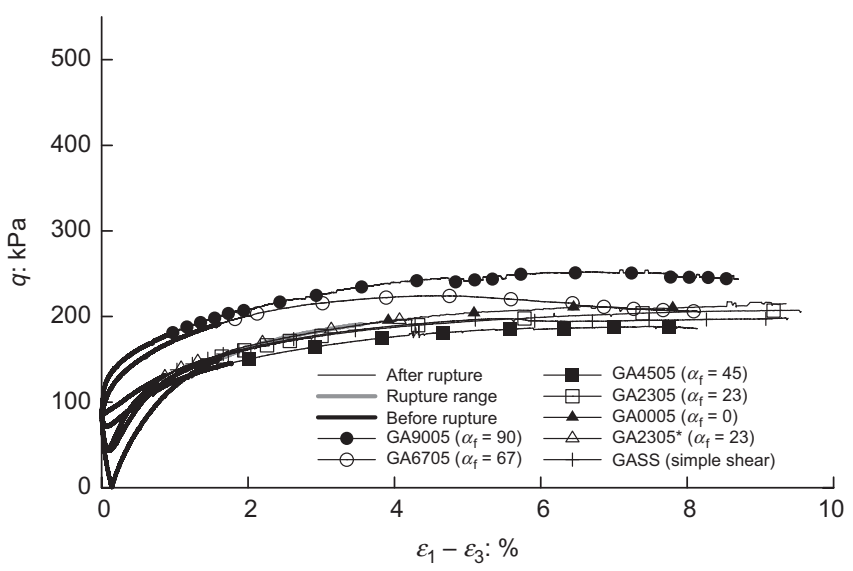

(c)

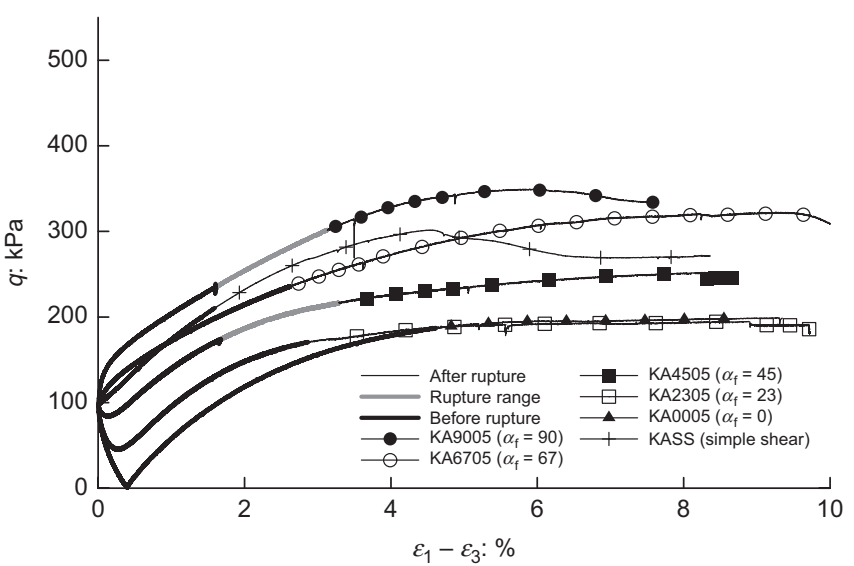

(b)

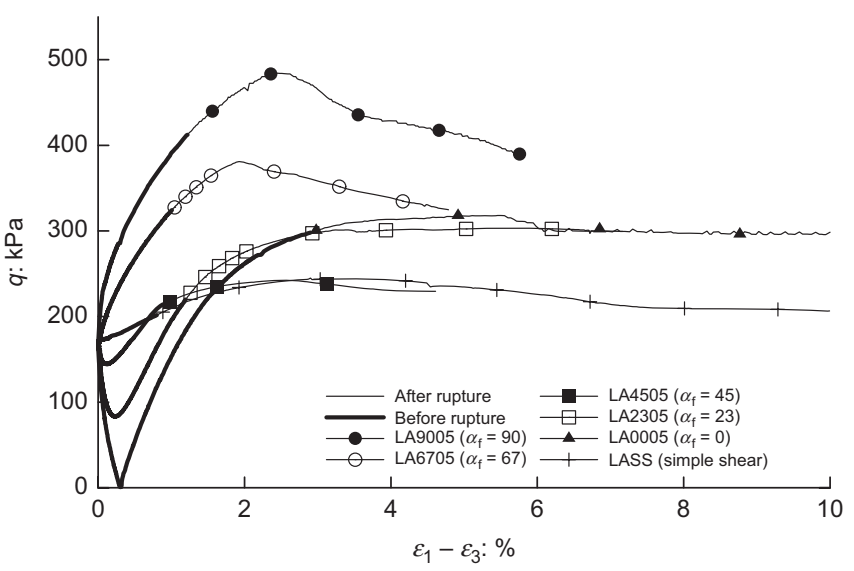

(d)

Fig. 8. Stress-strain curves in $q-\left(\varepsilon_{1}-\varepsilon_{3}\right)$, observed during the undrained shear stages of the suites of the constant- $\alpha_{\mathrm{d} \sigma}$ and simple shear HCA tests conducted from in situ stress conditions: (a) Oxford clay; (b) Kimmeridge clay; (c) Gault clay; (d) London clay 


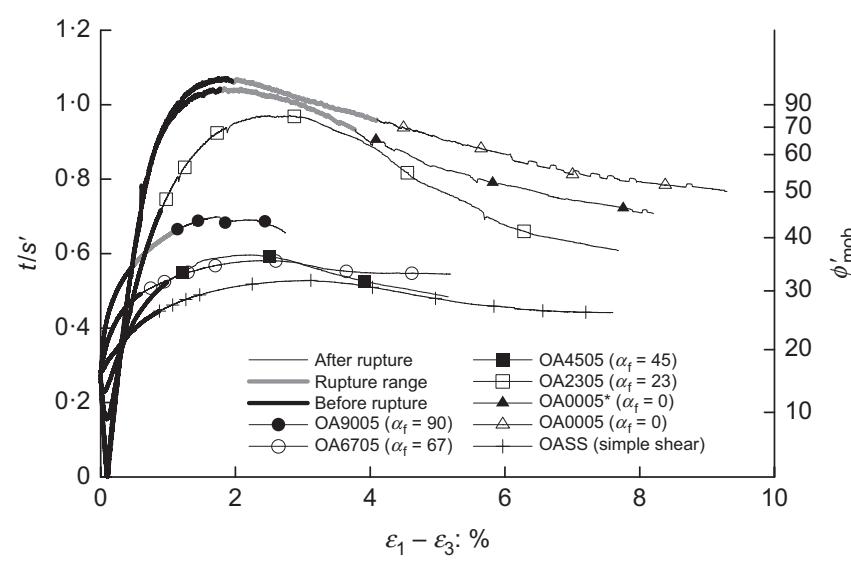

(a)

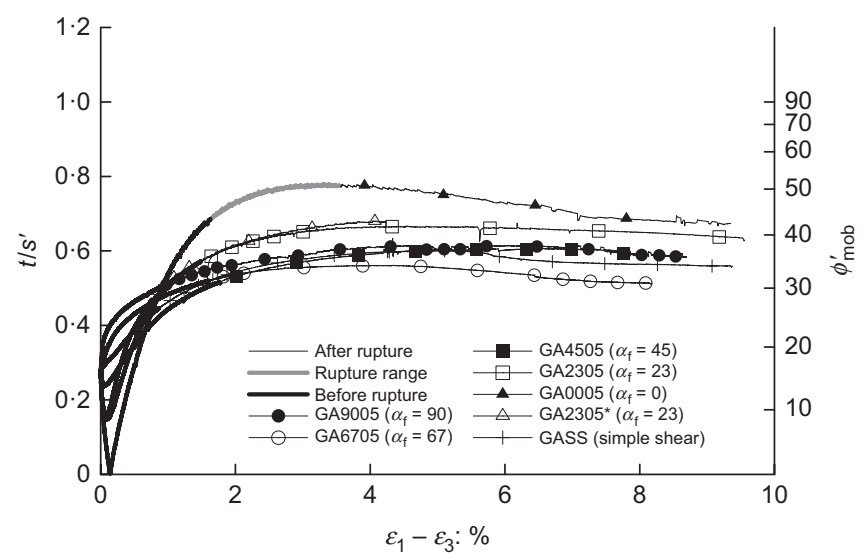

(c)

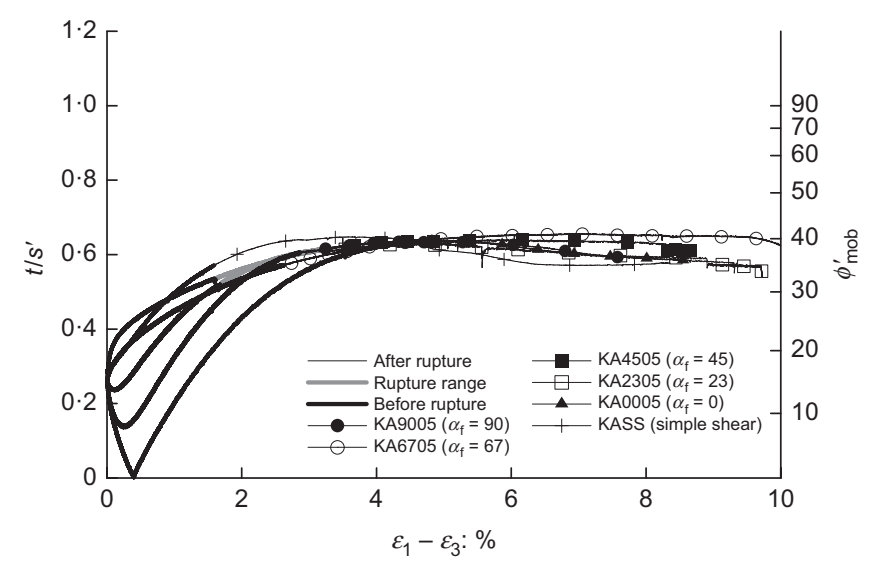

(b)

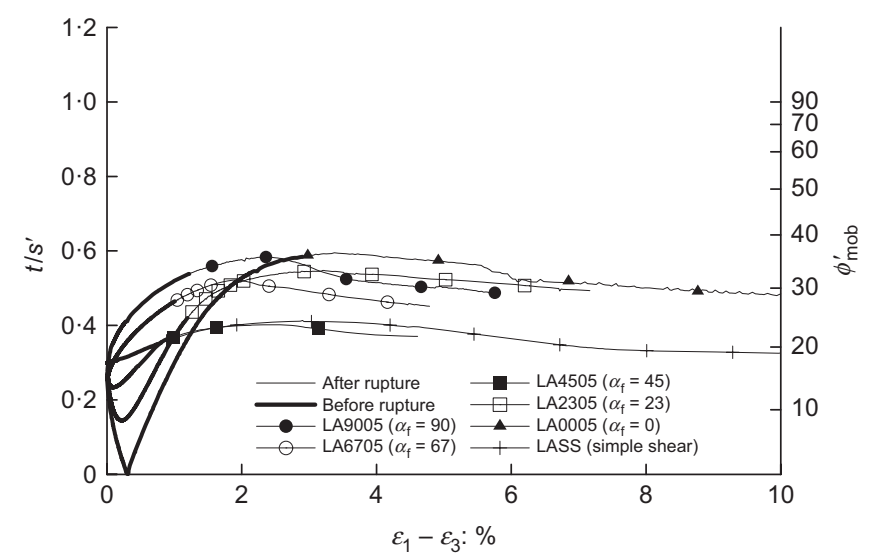

(d)

Fig. 9. Stress ratio-strain curves in $t / s^{\prime}-\left(\varepsilon_{1}-\varepsilon_{3}\right)$, observed during the undrained shear stages of the suites of the constant- $\alpha_{\mathrm{d} \sigma}$ and simple shear HCA tests conducted from in situ stress conditions: (a) Oxford clay; (b) Kimmeridge clay; (c) Gault clay; (d) London clay

of the constant- $\alpha_{\mathrm{d} \sigma}$ and HCA simple shear tests conducted from in situ stress conditions are shown in Figs 8(a)-8(d), while Figs 9(a)-9(d) present the corresponding $t / s^{\prime}-\left(\varepsilon_{1}-\varepsilon_{3}\right)$ plots.

The figures distinguish between the tests' pre-and-post shear localisation stages. It can be seen that first visible localisation generally preceded the peak $S_{\mathrm{u}}=q / 2$ and peak $t / s^{\prime}$ conditions. The peaks in $q$ and $t / s^{\prime}$ were not always concurrent, but all developed over the $1 \cdot 5-9 \%$ shear strain range. The dominantly torsional shear mode tests (that failed with $20^{\circ}<\alpha_{\mathrm{f}}<70^{\circ}$ ) provoked shear discontinuity formation at smaller shear strains than the other experiments. The observed failures were brittle, differing from those seen in tests on ductile, low-plasticity, overconsolidated clays, but the HCA tests exhibited far less marked displacementsoftening than triaxial tests on the same clays. Neither well-defined 'post-rupture' strengths (Burland, 1990) nor residual strength conditions were developed. It should be borne in mind that, as with other types of soil shear testing, HCA tests represent a non-uniform boundary value problem. The behaviour observed after shear surface formation is a consequence of interactions between the intact soil, the shear band material that is undergoing marked micro-fabric changes and the apparatus geometry. In most cases shear localisation started along one of the many natural discontinuities. The point of 'first rupture' is taken as the point at which shear localisation was first evident. However, the first shear localisation features did not necessarily persist and become parts of the final failure mechanism. In some cases, the progress of relative displacement skipped to different locations, and/or they were connected by a newly formed shear zone propagating through apparently intact parts. The process of localised shear mechanisms trying to find weaker zones, and when they could not, disrupting intact parts with higher resistance, took place progressively and led to the relatively large overall strains observed between first localisation and peak resistance. Nishimura (2006) and Brosse (2012) give further details of how the shear bands propagated during each experiment and how they interacted with the eventual final failure mechanisms.

The trajectories of the above tests' effective stresspaths are divided in two parts in Figs 10(a)-10(d) and Figs 11(a)-11(d), plotting the projections of the paths in the $\left[\left(\sigma_{z}-\sigma_{\theta}\right) / 2\right]-p^{\prime}$ plane and the $\tau_{z \theta}-\left[\left(\sigma_{z}-\sigma_{\theta}\right) / 2\right]$ plane, respectively. The mean effective stresses applying at final failure tended to increase with $\alpha_{\mathrm{f}}$, rising from minima $\alpha=0^{\circ}$ towards markedly higher $p^{\prime}$ when failing at $\alpha=90^{\circ}$, reflecting the negative $\mathrm{d}\left(\sigma_{z}-\sigma_{\theta}\right) / \mathrm{d}\left(2 p^{\prime}\right)$ slopes applying from the start of shearing up to the final dilative failure stages. The general trend of pre-failure 'dilative' behaviour for extensional loading $\left(\alpha_{\mathrm{d} \sigma}>45^{\circ}\right)$ and 'contractive' behaviour for compressional loading $\left(\alpha_{\mathrm{d} \sigma}<45^{\circ}\right)$ is a factor that contributed significantly to the clays' $S_{\mathrm{u}}$ anisotropy, as discussed below. Nishimura et al.'s (2007) wider ranging HCA study of London clay showed that similar patterns apply irrespective of the $b$ value at which samples are taken to failure. 
$\left\{\begin{array}{c}\delta \varepsilon_{\mathrm{r}} \\ \delta \varepsilon_{\theta} \\ \delta \varepsilon_{z} \\ \delta \gamma_{\theta z} \\ \delta \gamma_{z \mathrm{r}} \\ \delta \gamma_{r \theta}\end{array}\right\}=\left[\begin{array}{cccccc}\frac{1}{E_{\mathrm{h}}} & \frac{-\mu_{\mathrm{hh}}}{E_{\mathrm{h}}} & \frac{-\mu_{\mathrm{vh}}}{E_{\mathrm{v}}} & 0 & 0 & 0 \\ \frac{-\mu_{\mathrm{hh}}}{E_{\mathrm{h}}} & \frac{1}{E_{\mathrm{h}}} & \frac{-\mu_{\mathrm{vh}}}{E_{\mathrm{v}}} & 0 & 0 & 0 \\ \frac{-\mu_{\mathrm{hv}}}{E_{\mathrm{h}}} & \frac{-\mu_{\mathrm{hv}}}{E_{\mathrm{h}}} & \frac{1}{E_{\mathrm{v}}} & 0 & 0 & 0 \\ 0 & 0 & 0 & \frac{1}{G_{\mathrm{hv}}} & 0 & 0 \\ 0 & 0 & 0 & 0 & \frac{1}{G_{\mathrm{vh}}} & 0 \\ 0 & 0 & 0 & 0 & 0 & \frac{2\left(1+\mu_{\mathrm{hh}}\right)}{E_{\mathrm{h}}}\end{array}\right]\left\{\begin{array}{c}\delta \sigma_{\mathrm{r}} \\ \delta \sigma_{\theta} \\ \delta \sigma_{z} \\ \delta \tau_{\theta z} \\ \delta \tau_{z \mathrm{r}} \\ \delta \tau_{\mathrm{r} \theta}\end{array}\right\}$

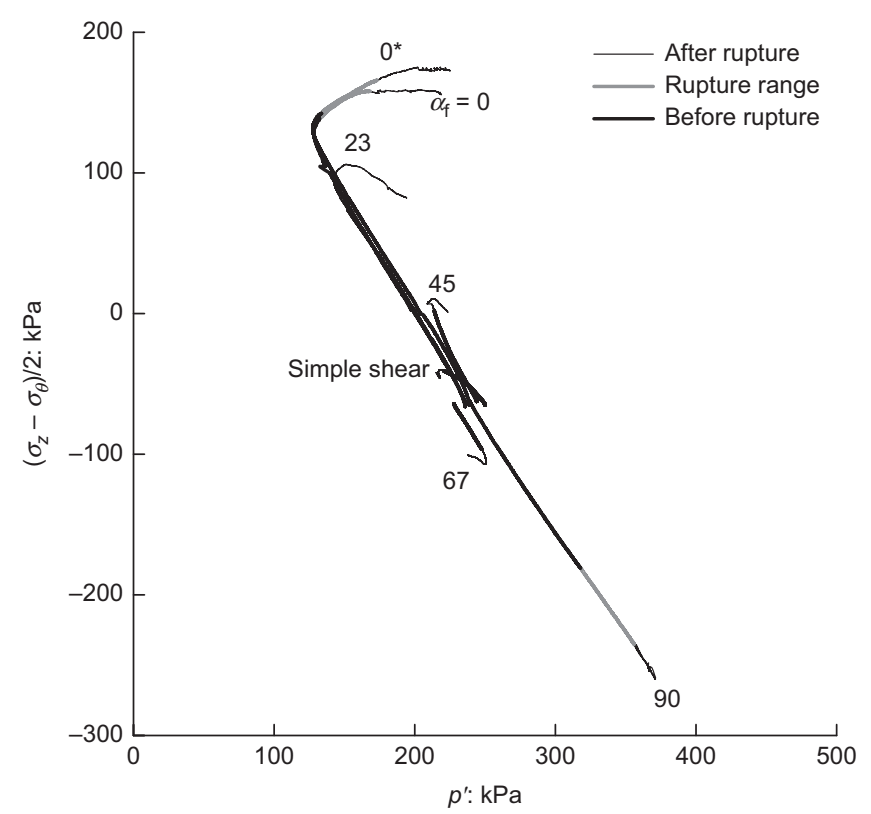

(a)

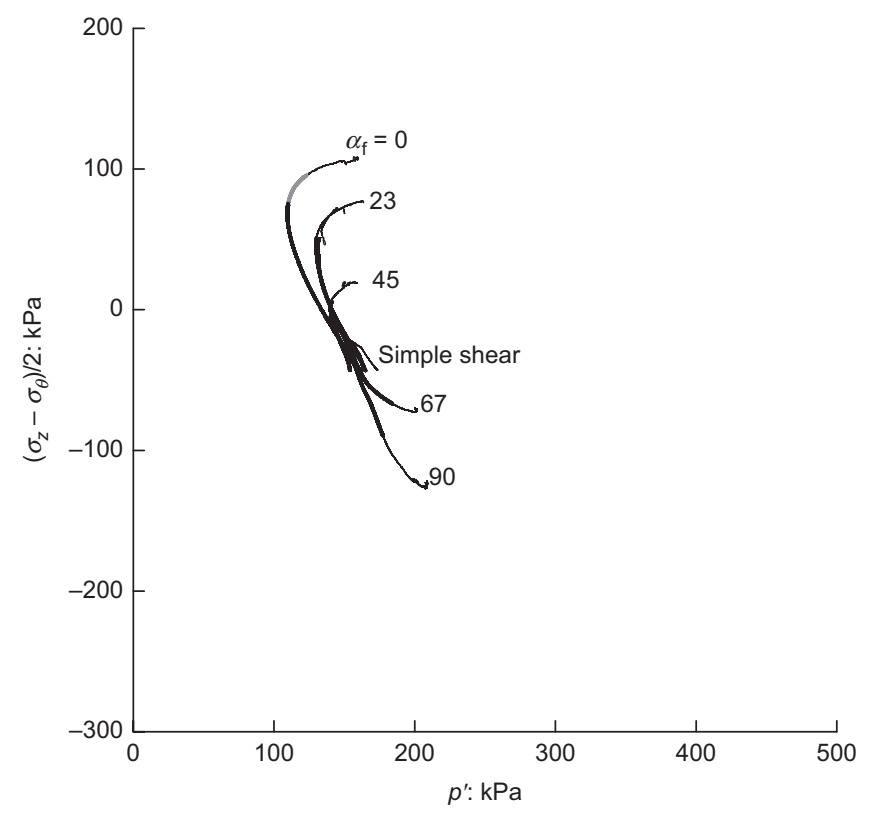

(c)

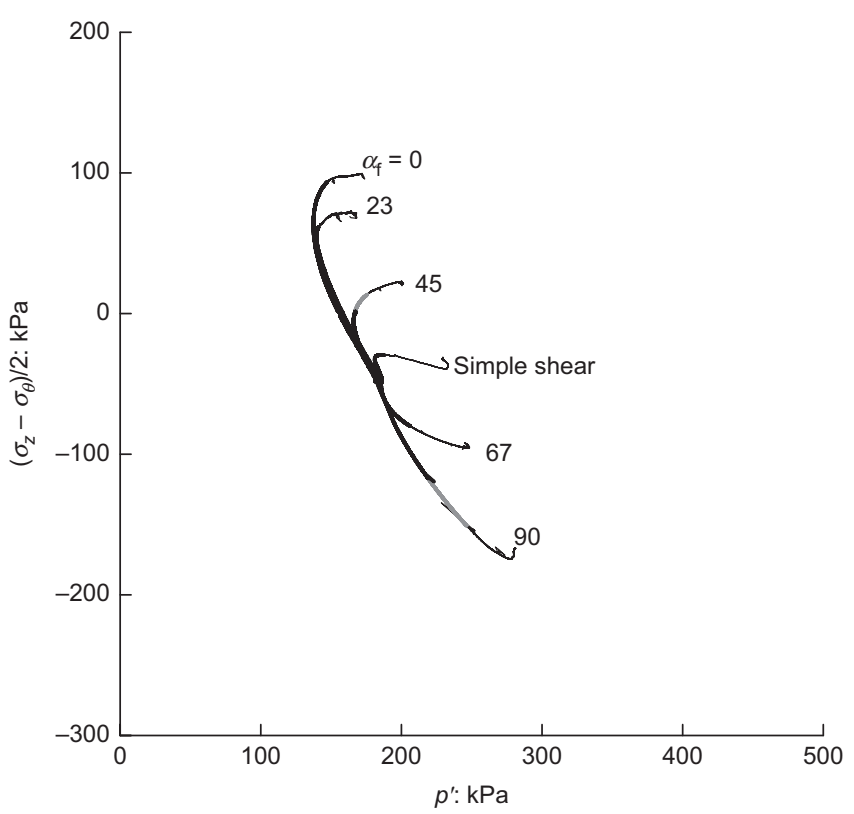

(b)

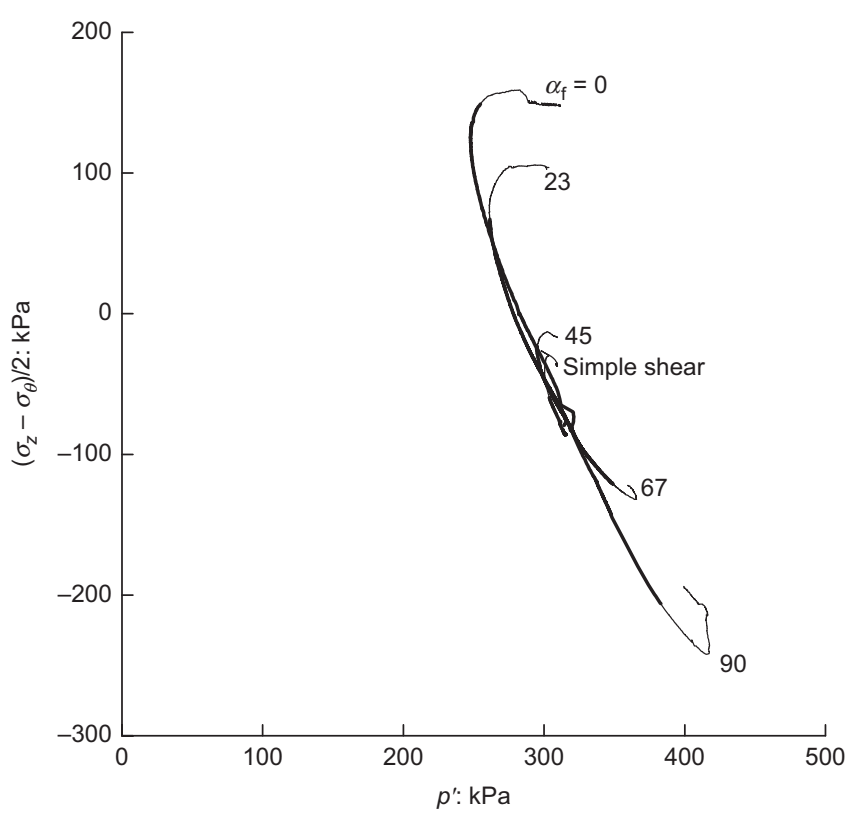

(d)

Fig. 10. Projection of the effective stress paths on the $\left[\left(\sigma_{z}-\sigma_{\theta}\right) / 2\right]-p^{\prime}$ plane for the constant- $\alpha_{\mathrm{d} \sigma}$ and simple shear HCA tests conducted from in situ effective stresses: (a) Oxford clay; (b) Kimmeridge clay; (c) Gault clay; (d) London clay 
The pre-failure 'dilatancy' characteristics appear to be related predominantly to the $\left(\varepsilon_{\mathrm{Z}}-\varepsilon_{\theta}\right)$ mode of deformation, with the $\gamma_{z \theta}$ mode having comparatively little effect. Nishimura (2006) and Brosse (2012) made theoretical estimates for the effective stress-path inclinations, $\mathrm{d}\left(\sigma_{z}-\sigma_{\theta}\right) / \mathrm{d}\left(2 p^{\prime}\right)$ by applying the cross-anisotropic elastic model given in equation (10) and employing parameters adopted from the small-strain stiffness measurements of Gasparre et al. (2007b), Hosseini Kamal (2012) and Brosse et al. (2017), who found that $E_{\mathrm{h}}^{\prime}>E_{\mathrm{v}}^{\prime}$ and anisotropic sets of $\mu_{\mathrm{vh}}, \mu_{\mathrm{hv}}$ and $\mu_{\mathrm{hh}}$ Poisson ratios applied to all four clays. It should be noted that according to the cross-anisotropic theory, the inclinations $\mathrm{d}\left(\sigma_{z}-\sigma_{\theta}\right) / \mathrm{d}\left(2 p^{\prime}\right)$ vary with $\alpha$ except for the special case employed in the presented tests where $b=0.5$.

The theoretical $\mathrm{d}\left(\sigma_{z}-\sigma_{\theta}\right) / \mathrm{d}\left(2 p^{\prime}\right)$ estimates and measurements are listed in Table 9. The input elasticity parameter values were measured on different specimens from the same block samples. The theoretical values of $\mathrm{d}\left(\sigma_{z}-\sigma_{\theta}\right) / \mathrm{d}\left(2 p^{\prime}\right)$ are predominantly determined by the ratio $E_{\mathrm{h}}^{\prime} / E_{\mathrm{v}}^{\prime}$, which can be determined through suites of triaxial tests involving local strain and shear wave velocity measurements; see Gasparre

Table 9. Predicted and measured $\mathrm{d}\left(\sigma_{z}-\sigma_{\theta}\right) / \mathrm{d}\left(2 p^{\prime}\right)$ stress-path gradients from undrained shearing stages of HCA tests maintaining $b=0 \cdot 5$

\begin{tabular}{c|l|c|l}
\hline \multirow{2}{*}{ Soil } & \multicolumn{2}{|l|}{$\begin{array}{l}\text { Measured stress } \\
\text { path gradients }\end{array}$} & $\begin{array}{l}\text { Ranges predicted from } \\
\text { anisotropic elastic } \\
\text { stiffness parameters }\end{array}$ \\
\cline { 2 - 3 } & Range & Average & \\
\hline $\begin{array}{c}\text { Oxford clay } \\
\text { Kimmeridge } \\
\text { clay }\end{array}$ & $-1 \cdot 5$ to $-1 \cdot 9$ & $-1 \cdot 7$ & $-2 \cdot 1$ to $-3 \cdot 3$ \\
$\begin{array}{c}\text { Gault clay } \\
\begin{array}{c}\text { London clay } \\
\text { (Unit B2c) }\end{array}\end{array}$ & -1.6 to $-2 \cdot 9$ & $-2 \cdot 3$ & -1.9 to -3 \\
\hline
\end{tabular}

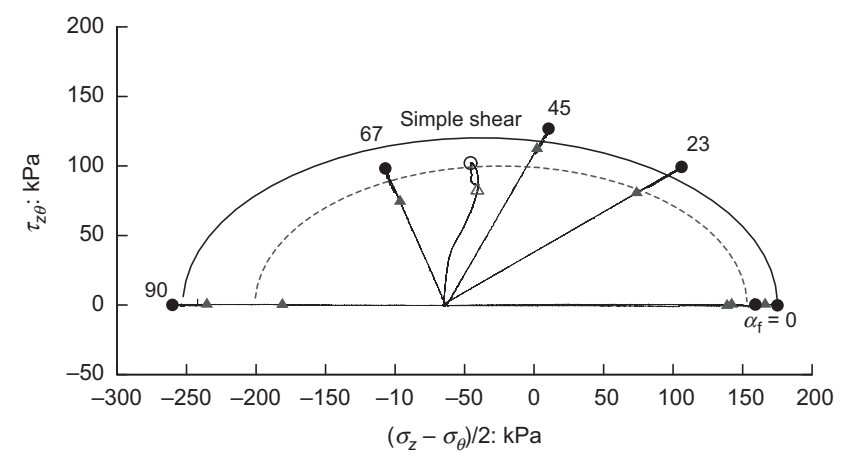

(a)

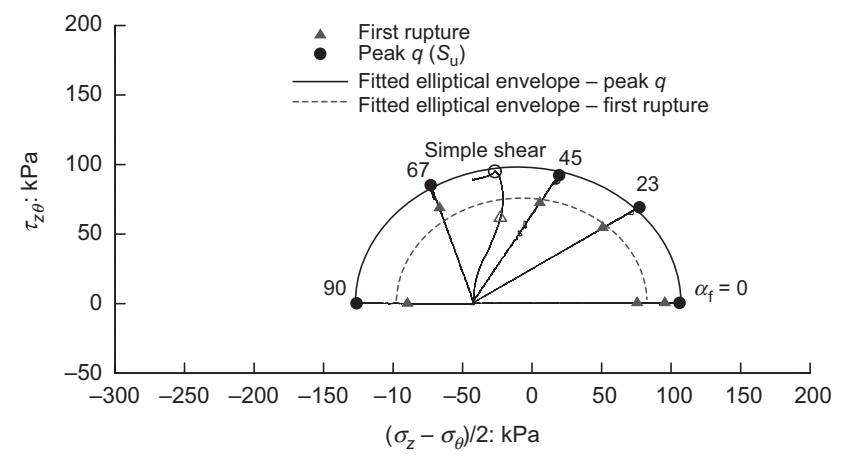

(c) et al. (2007b), Nishimura (2014) or Brosse et al. (2017). Ratios between 1.6 and 3.1 are found for the four clays, with the upper and lower limits applying to the London and Gault clays, respectively. The four clays' initial gradients varied between tests but gave average values in the $-2 \cdot 0 \pm 0 \cdot 3$ range. While predictions from the simplified analysis have the same negative sign, they overestimate the initial the gradients and so under-predict the influence of changes in $\left(\varepsilon_{\mathrm{z}}-\varepsilon_{\theta}\right)$ on $p^{\prime}$, except for the Gault clay case. The adopted anisotropic ratios of clay stiffness were established at very small strains (less than $0.001 \%$ ) and may not be fully applicable to the whole range represented in Fig. 10, although the $\mathrm{d}\left(\sigma_{z}-\sigma_{\theta}\right) / \mathrm{d}\left(2 p^{\prime}\right)$ inclinations did not vary greatly from small strains, over the non-linear, elasto-plastic phase, until failure was approached.

It might be argued that the predicted and measured ratios may have differed because the input stiffness ratios were measured under axisymmetric stress states that were altered in the HCA tests by applying non-symmetric stresses in the $b$-change stage. Semi-quantitative evaluation can be made following the anisotropic Young's moduli model based on the effective stress raised by constant exponents, as outlined, for example, by Hoque et al. (1996). However, Nishimura (2006), Gasparre et al. (2007b), Hosseini Kamal (2012) and Brosse et al. (2017) report that the clays' elastic stiffness anisotropy is insensitive to small changes in effective stress states, as quantified by the exponent values set for the above model. Applying, for example, Nishimura's LA series London clay stiffness data indicates that the $b$-change stage effective stress changes would lead to a $1 \cdot 6 \%$ change in $E_{\mathrm{h}}^{\prime} / E_{\mathrm{v}}^{\prime}$ that would not affect any of the clays' $\left(\sigma_{z}-\sigma_{\theta}\right) / d\left(2 p^{\prime}\right)$ inclinations significantly.

\section{Anisotropy in undrained shearing resistance}

First the HCA test outcomes are reported in total stress terms, considering the clays within the framework of a purely cohesive (Tresca) material whose shear strength is

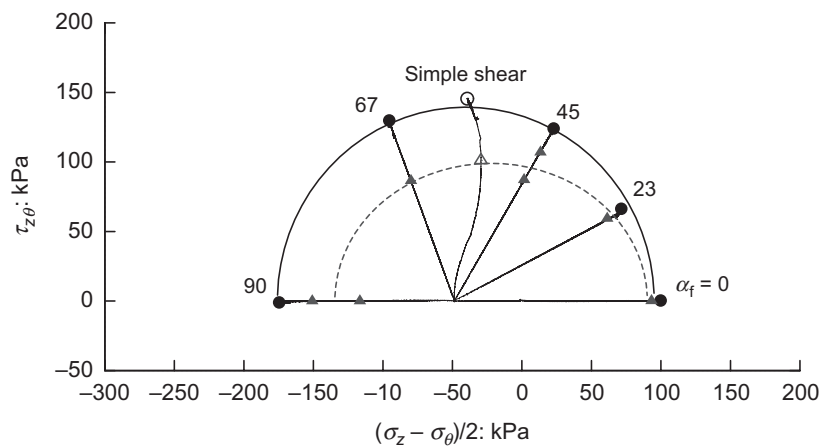

(b)

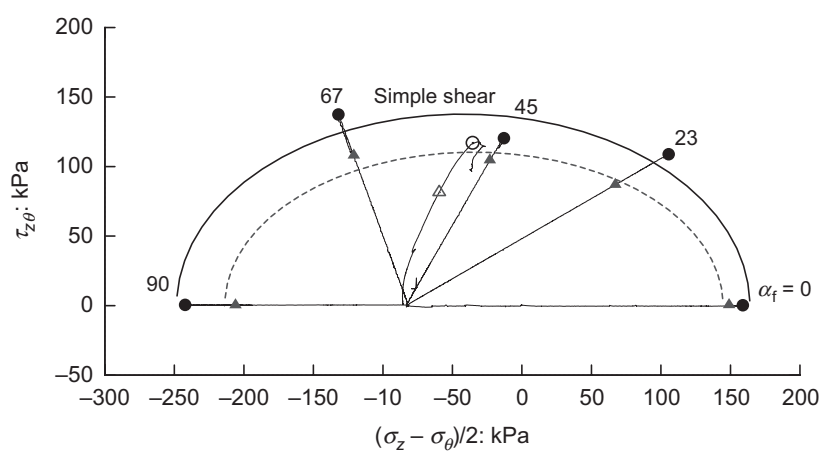

(d)

Fig. 11. Projection of the stress paths on the $\tau_{z \theta}-\left[\left(\sigma_{z}-\sigma_{\theta}\right) / 2\right]$ plane for the constant- $\alpha_{\mathrm{d} \sigma}$ and simple shear HCA tests conducted from in situ effective stresses: (a) Oxford clay; (b) Kimmeridge clay; (c) Gault clay; (d) London clay 


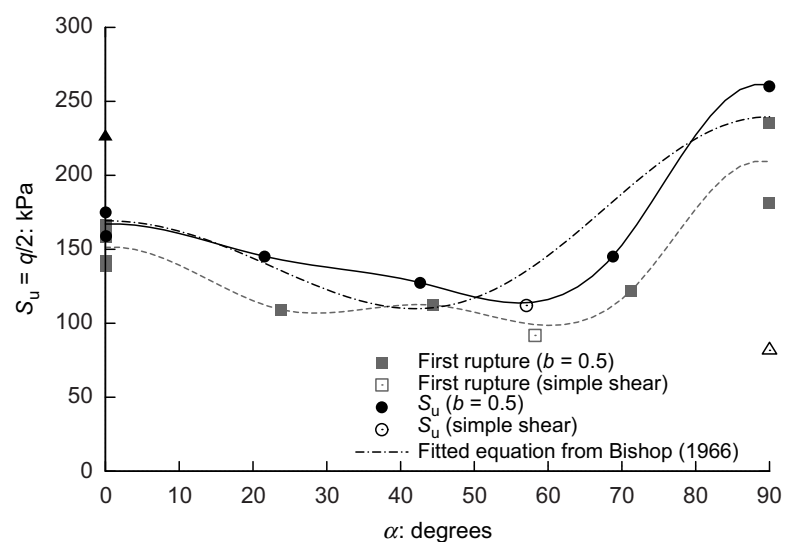

(a)

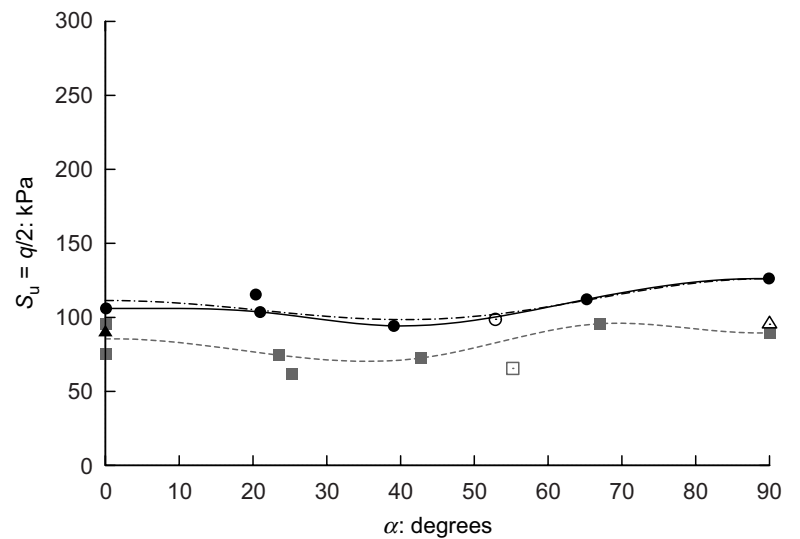

(c)

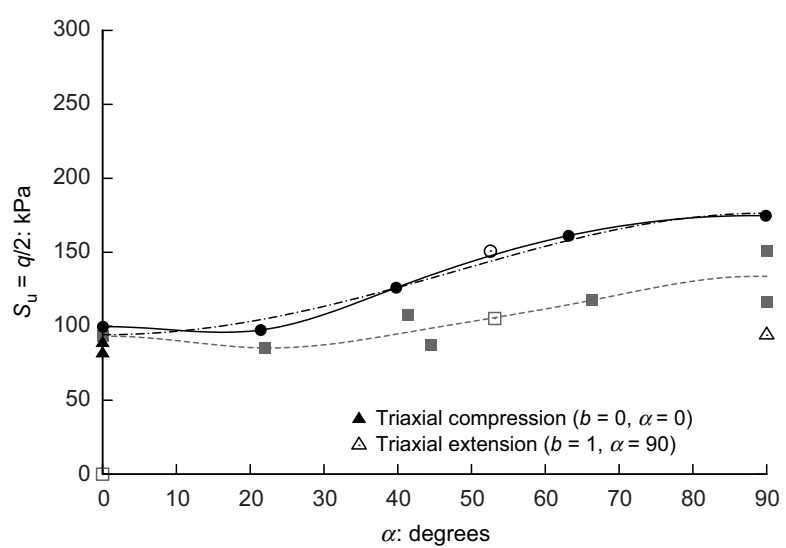

(b)

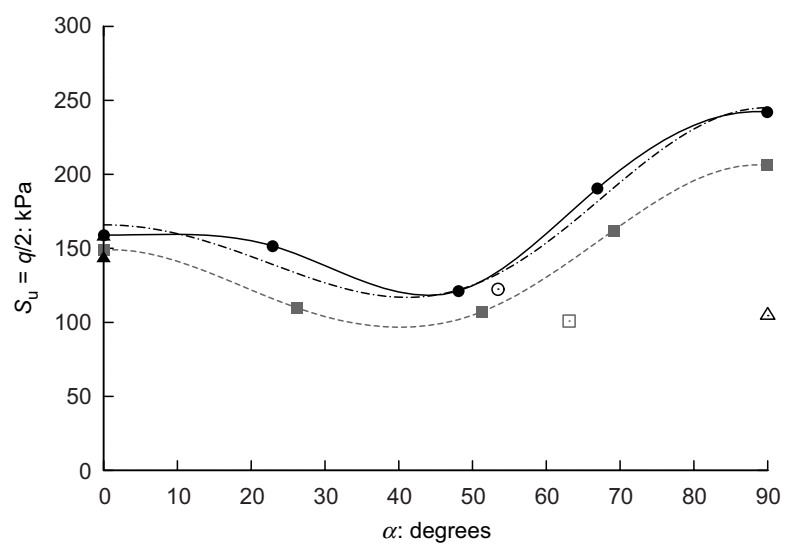

(d)

Fig. 12. Variations in undrained peak shear strength $S_{\mathrm{u}}$ with the orientation of major principal stress at failure $\alpha_{\mathrm{f}}$ covering both the constant- $\alpha_{\mathrm{d} \sigma}$ and simple shear HCA tests conducted from in situ stresses: (a) Oxford clay; (b) Kimmeridge clay; (c) Gault clay; (d) London clay

independent of $p$. For an isotropic material following this framework, the peak strength envelope forms a circle centred on the origin in Figs 11(a)-11(d). All of the four clays deviate markedly from this pattern. Figs 12(a)-12(d) detail the clays' variations of undrained shear strength, $S_{\mathrm{u}}$, with $\alpha_{\mathrm{f}}$, covering both the constant- $\alpha_{\mathrm{d} \sigma}$ and simple shear tests conducted from in situ effective stress conditions, emphasising the differences between the strengths developed at the first rupture and ultimate peak conditions. The variation has also been fitted on Figs 12(a)-12(d) using the empirical equation proposed by Bishop (1966)

$$
S_{\mathrm{u}}=S_{\mathrm{u} 0}\left[1-a_{1} \sin ^{2}(\alpha)\right]\left[1-a_{2} \sin ^{2}(2 \alpha)\right]
$$

where $S_{\mathrm{u} 0}$ is the undrained strength at $\alpha=0^{\circ}$, and $a_{1}$ and $a_{2}$ are fitting parameters.

A summary is made in Fig. 13 of the four clays' trends with $\alpha$ of peak $S_{\mathrm{u}}=q / 2$. Although the samples were all taken from broadly similar depths, the London clay specimens were tested at higher effective stresses than the other clays (see Tables 4-7) because, as noted earlier, they had been covered by $6 \mathrm{~m}$ of River Terrace gravels. It is evident that the Gault and Kimmeridge clays developed generally lower undrained shear strengths than the Oxford clay, and the London clay specimens tested at significantly higher effective stresses. The Gault clay showed the least variation of $S_{\mathrm{u}}$ with $\alpha$, with its minimum applying when the $\sigma_{1}$ axis was rotated by around $40^{\circ}$ from the vertical and its maximum when $\alpha=90^{\circ}$. The Kimmeridge clay developed a similar $\alpha=0^{\circ} S_{\mathrm{u}}$ value to the Gault, but manifested its minimum at a lower $\alpha$ (in the range $0^{\circ}$ to $20^{\circ}$ ) and a $50 \%$ higher maximum $S_{\mathrm{u}}$ at $\alpha=90^{\circ}$. The Oxford and London clays developed their minima with $\alpha$ around $45^{\circ}$, and $S_{\mathrm{u}}$ maxima at $\alpha=90^{\circ}$ that were double their intermediate $\alpha$ minima.

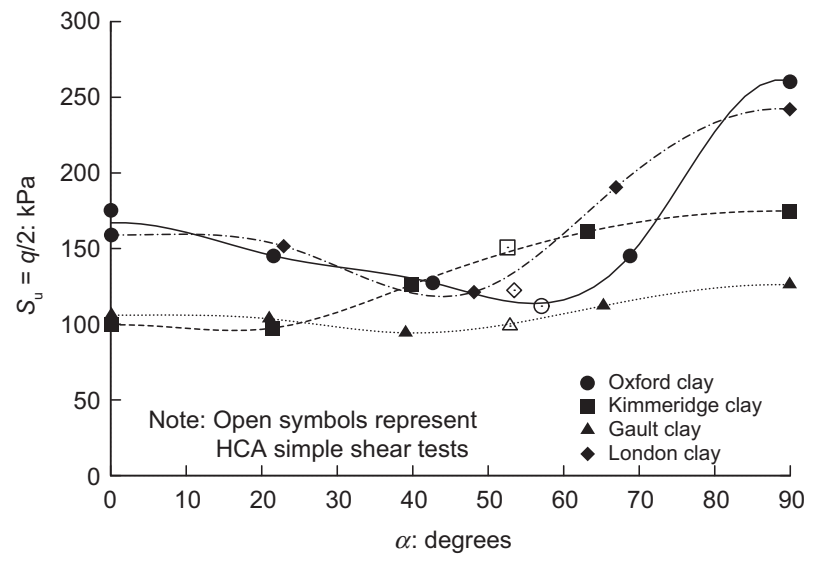

Fig. 13. Summary of the four clays' trends of variation of undrained peak strength $S_{\mathrm{u}}$ with $\alpha_{\mathrm{f}}$ from constant- $\alpha_{\mathrm{d} \sigma}$ and simple shear HCA tests conducted from in-situ effective stresses

Overall, the four clays share similar hierarchies in undrained shear strength: $S_{\mathrm{u}}$ is lowest when $\alpha$ lies between $10^{\circ}$ and $45^{\circ}$, when the specimens' failure mechanisms could best exploit pre-existing horizontal fissures or bedding features, while $S_{\mathrm{u}}$ is highest when $\alpha=90^{\circ}$. The most intensively fissured Gault showed the least variation between these limits, while the London and Oxford clays showed the most marked $S_{\mathrm{u}}$ anisotropy. The simple shear tests, which failed at $\alpha$ around $50-60^{\circ}$ and $b \approx 0 \cdot 4-0 \cdot 6$, gave relatively low $S_{\mathrm{u}}$ values that fit well with the constant- $\alpha_{\mathrm{d} \sigma}$ experiments anisotropic $S_{\mathrm{u}}$ trends. 
Influence of initial effective stress level on peak shear strength As was demonstrated in Figs 8-10, the four brittle, plastic, overconsolidated clays reach their peak shear strengths shortly after developing shear discontinuities and do not manifest any extended period of dilative behaviour. Hence $S_{\mathrm{u}}$ depends on the effective stress state under which the envelope is first engaged, and is not uniquely related to water content or void ratio (see, for example, Jardine et al. (2004)). Specimens possessing a geologically controlled effective stress failure envelope can exhibit a variety of $S_{\mathrm{u}}$ values at similar water contents, depending principally on variations in their initial effective stress states. Imposing the correct effective stress and $K_{0}$ conditions is therefore critical when attempting to measure the $S_{\mathrm{u}}$ anisotropy that would apply in the field. It is generally not possible to impose such conditions when conducting triaxial compression tests on inclined samples.

As noted at the outset and illustrated in Fig. 1, the stiff clays manifest en-echelon families of curved effective stress peak failure envelopes and state boundary surfaces under triaxial test conditions. The envelopes vary with each soil's structure and depth and each envelope presents reductions in $t / s^{\prime}$ with increasing mean effective stress. While it was not possible to explore in detail how these features affected each clay's effective stress shear strength anisotropy, Brosse (2007) and Nishimura et al. (2008) studied effective stress level dependency of the strength in simple shear tests on London clay samples as outlined in Table 7. Fig. 14 summarises the peak $t-s^{\prime}$ conditions developed in four simple shear tests conducted on samples taken from a level $16 \mathrm{~m}$ below the original gravel surface, $10 \mathrm{~m}$ below the top of the clay. Four were tested from in situ stress conditions, two from lower initial effective stresses and one from elevated consolidation effective stresses. The observed curved failure trend envelope represents that applying under the $45^{\circ}<\alpha_{\mathrm{f}}<55^{\circ}$ and $0 \cdot 4<b<0.6$ 'simple shear' range. This curved envelope has comparable shapes and scales to the triaxial compression envelopes for London clay samples at 6-12 m depth outlined in Fig. 14. The $t / s^{\prime}$ ratios applying to tests involving $\alpha$ rotation are also likely to decline with increasing mean effective stress $p^{\prime}$. This trend has been confirmed in subsequent additional HCA tests on Kimmeridge clay samples.

Peak shear strength anisotropy in terms of mobilised $\mathrm{t} / \mathrm{s}^{\prime}$ ratios As shown in Fig. 10, all four clays showed significant variation with $\alpha$ in their peak failure $p^{\prime}$ and $s^{\prime}$ values as a result of the pre-failure $\mathrm{d}\left(\sigma_{z}-\sigma_{\theta}\right) / \mathrm{d}\left(2 p^{\prime}\right)$ gradients listed in

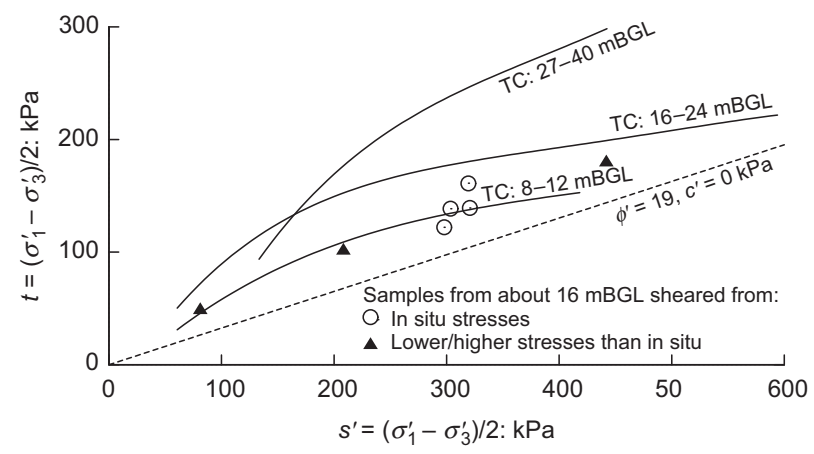

Fig. 14. Peak $t-s^{\prime}$ conditions developed in simple shear HCA tests conducted on London clay samples taken from the $16 \mathrm{~m}$ depth below original gravel surface level, considering tests sheared from in-situ and other effective stress levels (modified from Nishimura et al., 2008). The $c^{\prime}=0, \phi^{\prime}=19^{\circ}$ line represents the fissure shear strength
Table 9. This feature contributed much to the different anisotropy patterns seen for $S_{\mathrm{u}}$ (Fig. 13) and peak $t / s^{\prime}$ (shown subsequently in Fig. 16), with lower $\alpha$ leading to a smaller $S_{\mathrm{u}}$ for a given $t / s^{\prime}$ due to a reduced $s^{\prime}$ value at failure. This relationship between $S_{\mathrm{u}}$ and peak $t / s^{\prime}$ is further skewed by the curvature of the peak failure envelopes associated with each $\alpha$ value, with $t / s^{\prime}$ decreasing as $s^{\prime}$ increases. Further testing is required to provide a comprehensive assessment for each clay of the curved effective stress peak shear strength envelopes corresponding to fixed values of $b$ and $\alpha$.

The first rupture and peak conditions identified for each clay in undrained tests from in situ stress conditions are reported in Figs 15(a)-15(d) by plotting $t / s^{\prime}$ against $\alpha$, while an overall summary plot for the peak $t / s^{\prime}$ points is given in Fig. 16 that shows at its right-hand side equivalent values of $\phi_{\mathrm{mob}}^{\prime}=\sin ^{-1}\left(t / s^{\prime}\right)$. As with the $S_{\mathrm{u}}$ traces, the $t / s^{\prime}$ minima develop at intermediate $\alpha$, although the range of angles is relatively larger, falling between $45^{\circ}$ and $70^{\circ}$. The clays show their $t / s^{\prime}$ maxima at $\alpha_{\mathrm{f}}=0^{\circ}$, rather than the $90^{\circ}$ orientation applying to $S_{\mathrm{u}}$, reflecting the lower effective stresses applying at smaller $\alpha$ values that were discussed above. The mobilised $\phi^{\prime}$ angles are all relatively high, reflecting envelope curvature and potentially limited cohesive bonding in the geologically aged clays. As with the $S_{\mathrm{u}}$ plots, the simple shear experiments led to peak $t / s^{\prime}$ points that were compatible with the $\alpha_{\mathrm{d} \sigma}$ experiments conducted over the same $\alpha$ range.

Brosse's (2012) detailed analysis showed that the two $\alpha_{\mathrm{f}}=0^{\circ}$ Oxford clay tests both developed limited tensile circumferential stresses, with $\sigma_{3}^{\prime}=\sigma_{\theta}^{\prime}$, and also exhibited a clear pattern of vertical tensile cracks in the samples. The Oxford clay $\alpha_{\mathrm{f}}=22.5^{\circ}$ test also failed close to the no-tension line (that is the line corresponding to $\sigma_{3}^{\prime}=0$ and $t / s^{\prime}=1$ ). As summarised in Table 1 the Oxford clay samples' meso-fabrics were unique in displaying primarily bedding and no fissuring; these features enhanced its shear strength at low $\alpha$ values. Although impossible under ordinary triaxial conditions where pore water pressures cannot exceed the cell pressure and negative $\sigma_{3}^{\prime}$ values can never be applied, negative effective circumferential stresses can develop in HCA tests conducted with $b>0$ and low $\alpha$ values, as the annular geometry allows true circumferential tension. However, the non-uniformities developed by samples at late test stages, and the limited magnitudes (a few $\mathrm{kPa}$ ) of the recorded negative stresses make it difficult to draw reliable detailed conclusions regarding this Jurassic clay's true cohesive strength, if any. Triaxial compression tests performed on Oxford clay by Hosseini Kamal (2012) on similar samples led to much higher $S_{\mathrm{u}}$, with samples manifesting a more extended dilative phase (see Table 2 and Fig. 12). Tests conducted at low effective stress under axi-symmetric triaxial conditions on strong, heavily overconsolidated clays may overestimate the undrained strength.

It should be noted that the observed variation of the strength with $\alpha_{\mathrm{f}}$ is not solely due to the meso-fabric. Nishimura et al. (2007) indicated for London clay that even reconstituted specimens exhibited significant strength anisotropy, but with a different pattern to the natural specimens. The anisotropy of the natural samples represents the combined outcome of the intrinsic microstructure, as applying at deposition, and the subsequent geological history which imparted, among other processes, burial and compaction, diagenesis, fissuring, stress relief, vegetative impact, freeze-thaw cycles and weathering.

\section{Influence of intermediate principal stress on peak shear strength}

As noted previously, the influence on shear strength of $\sigma_{2}^{\prime}$, as expressed by the imposed $b$ value, was not the principal 


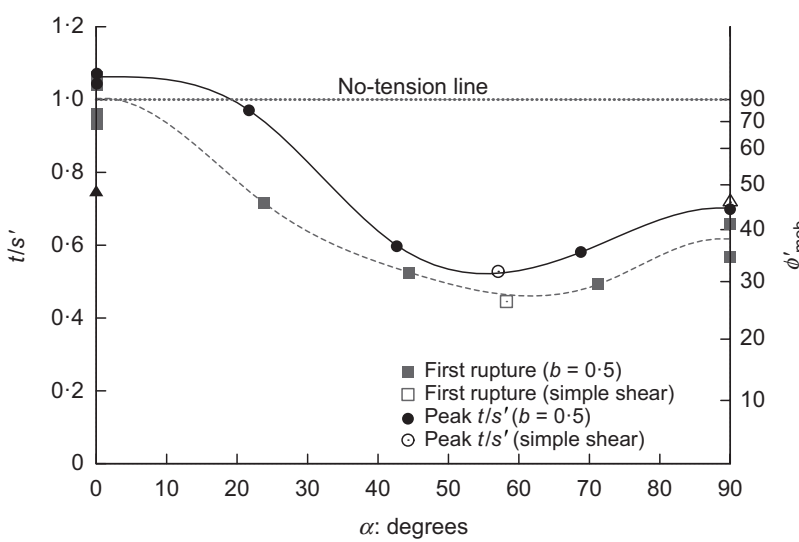

(a)

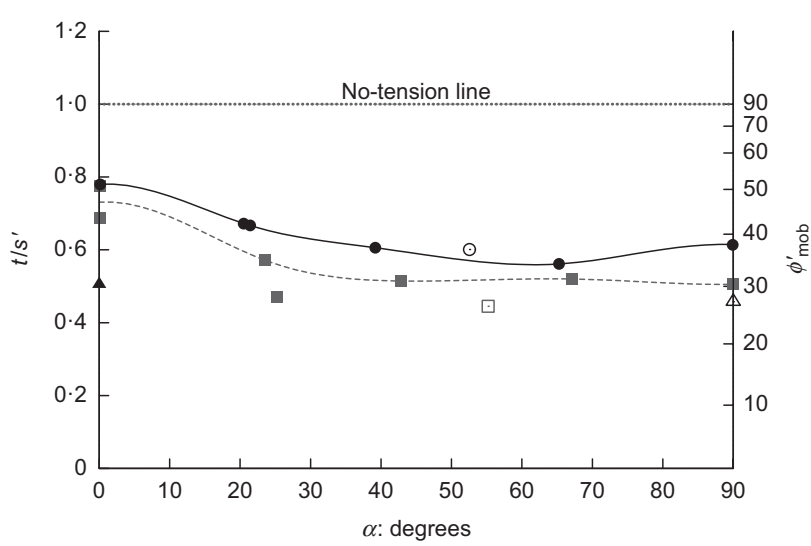

(c)

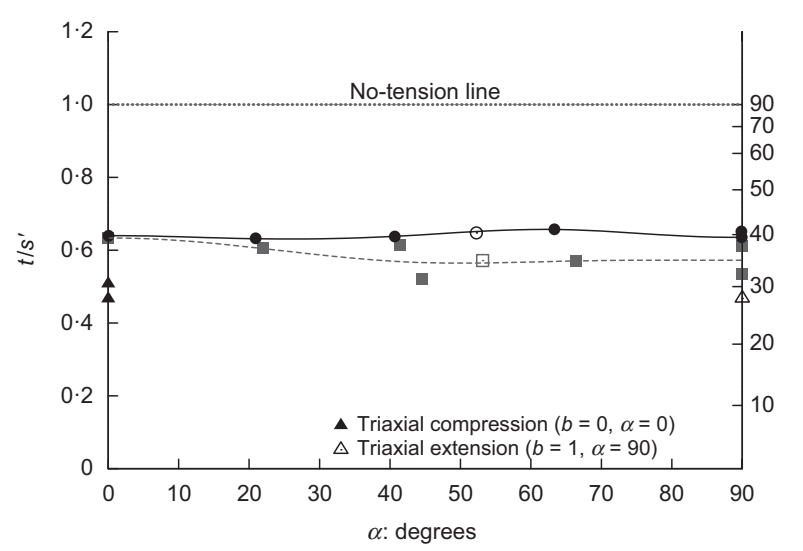

(b)

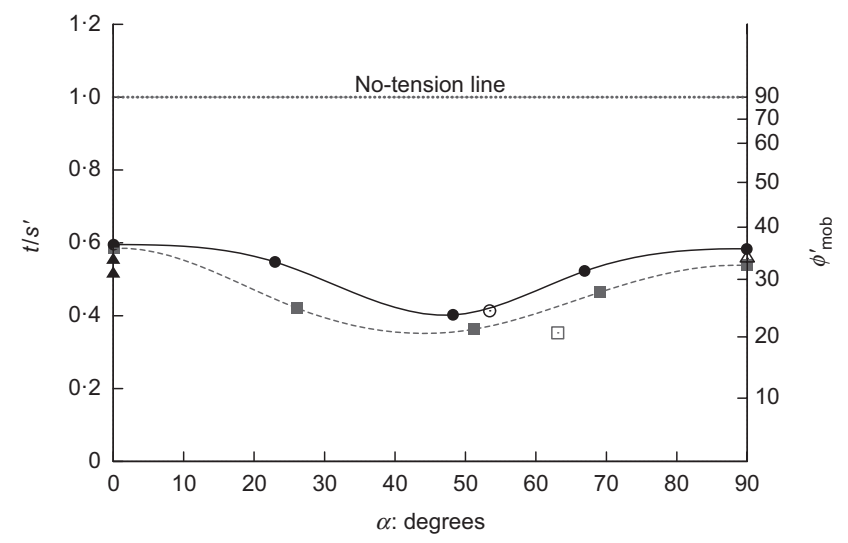

(d)

Fig. 15. Variations in stress ratio $t / s^{\prime}$ with the orientation of major principal stress at failure $\alpha_{\mathrm{f}}$ covering both the constant- $\alpha_{\mathrm{d} \sigma}$ and simple shear HCA tests conducted from in situ stresses: (a) Oxford clay; (b) Kimmeridge clay; (c) Gault clay; (d) London clay. Right-hand side shows equivalent mobilised angle of shearing resistance. Note that when $b=0 \cdot 5, t / s^{\prime}=q l\left(2 p^{\prime}\right)$, see equations (7) and (8)

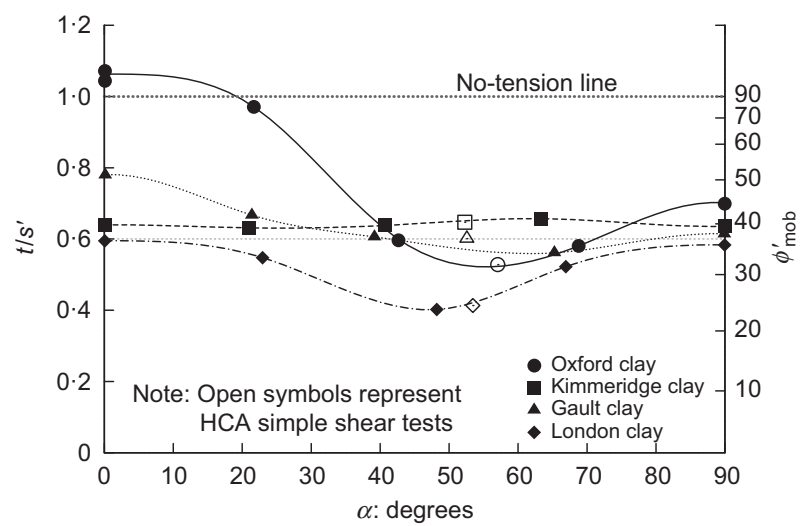

Fig. 16. Summary for all four clays of peak $t / s^{\prime}$ trends against $\alpha_{\mathrm{f}}$ in undrained tests sheared from in situ stresses. The right-hand side shows equivalent mobilised angle of shearing resistance. Note that when $b=0 \cdot 5, t / s^{\prime}=q /\left(2 p^{\prime}\right)$, see equations (7) and (8)

focus of the present study, where most tests were conducted with $b=0 \cdot 5$. Nonetheless, the peak shear strengths obtained from triaxial compression $\left(b=0, \alpha=0^{\circ}\right)$ and extension $(b=1$, $\left.\alpha=90^{\circ}\right)$ tests are plotted for comparison in Figs 12 and 15 . The lower strengths developed in triaxial extension as compared to the $b=0.5 \alpha=90^{\circ}$ case are noticeable, especially in terms of $S_{\mathrm{u}}$. This feature may reflect the more restricted set of planes on which samples can fail in HCA tests under conditions where the intermediate principal stress direction is constrained to always be radial.
Influence of structure on shear strength anisotropy

As highlighted above, wherever a purely cohesive $\left(S_{\mathrm{u}}\right)$ or a purely frictional $\left(t / s^{\prime}\right)$ model is considered, the lowest strengths were recorded at intermediate $\alpha$ values, usually in the $30-70^{\circ}$ range. Brosse (2012) and Nishimura (2006) observed that these tests usually led to strain localisation along predominantly horizontal or low-angled $\left( \pm 20^{\circ}\right.$ from the horizontal) shear planes or shear bands. This is to be expected as in these loading orientations one of the set of planes of maximum shear stress ratio is near horizontal. This suggests that horizontal planes are weaker against shear. This is coherent with Wilkinson's (2011) observations on the microstructure of those clays, which show that the platy clay particles are preferably horizontally orientated. The Oxford clay tested presents the strongest alignment of particles, which combined with the presence of beddings observed at the meso-structure level to explain the strong strength anisotropy observed in this soil. London and Gault clay presented milder preferential orientation of particle while Kimmeridge clay had the lowest level. Although potential routes for developing constitutive models that match the experimental results are not discussed here, Brosse (2012) demonstrates how her experiments' anisotropic failure conditions can be characterised by following the criteria and approach set out by Pietruszczak \& Mroz (2000).

\section{PRACTICAL IMPLICATIONS}

The HCA experiments demonstrate varying degrees of anisotropy in all four clays. Referring the $S_{\mathrm{u}}$ trends displayed in Fig. 13 for near plane strain, $b=0 \cdot 5$, conditions to the 
triaxial compression undrained shear strengths listed in Table 2 shows that the latter could be non-conservative over a critical range of intermediate $\alpha$ values. If free to form under foundations, dams, retaining walls or in slopes, undrained collapse mechanisms could exploit the experimentally proven anisotropy as they start the progressive failure that eventually leads to residual shear strength development (Potts et al., 1997). Analyses based on peak triaxial compression shear strengths would be misleadingly nonconservative for the London, Gault, Kimmeridge or Oxford clays due to both their anisotropy and their brittleness. Equally, in cases that involve uniform and primarily vertical or horizontal plane strain loading, standard triaxial compression tests could underestimate peak field shear strengths.

As noted earlier, the shear strength anisotropy can also be expected to affect the displacements developed by fully stable engineering works. Geotechnical structures often develop zones of contained failure under safe working conditions that, together with the non-linear stiffness of the soil mass, control the overall patterns and scales of ground movements; see Jardine et al. (1986), Addenbrooke et al. (1997) or Potts \& Zdravkovic (2001). New numerical analyses with anisotropic criteria (such as those discussed by Brosse (2012)) are required to explore how the stiffness and shear strength anisotropy proven by the HCA experiments will impact on a wide range of geotechnical engineering applications. Equivalent analyses of how shear strength anisotropy affects embankment foundation stability with low-OCR clays indicate that the impact will be considerable (Zdravkovic et al., 2002). The same authors show that no single index strength can be adopted as fitting all geometries. For example, the direct simple shear (DSS) strengths, which are often adopted as 'practical' intermediate values between triaxial compression and extension, can either be safe or unsafe depending on the embankment slope angle. The anisotropy reported for the stiff clays shows quite different patterns in which, for example, passive failures invoke higher strengths than those under active conditions, and the implications for practice remain to be explored systematically.

\section{SUMMARY AND CONCLUSIONS}

Characterising the shear strength behaviour of heavily overconsolidated, stiff-to-hard plastic clays is crucial to assessing their stability and also influential when predicting ground movements in many geotechnical engineering applications. The anisotropy in shear strength of the London, Gault, Kimmeridge and Oxford clays has been established through advanced HCA experiments on multiple highquality samples taken at similar depths from inland sites with well-established geotechnical profiles. Ten main conclusions are drawn.

(a) The clays' micro- and macro-fabrics led to variable degrees of shear strength anisotropy. Overall, the Oxford clay showed the most important anisotropy due to its clear horizontal bedding and absence of fissuring. The lowest degree of anisotropy in terms of the Tresca criterion was shown by the Gault, while the Kimmeridge clay showed the least anisotropy in terms of the Mohr-Coulomb criterion.

(b) Simple shear strength tests, which failed at intermediate $\alpha_{\mathrm{f}}$, gave lower range shear strengths (in terms of both $S_{\mathrm{u}}$ and $t / s^{\prime}$ ) in all but the Kimmeridge clay.

(c) All tests showed shear localisation before achieving peak shear strength. This developed earliest in intermediate $\alpha_{\mathrm{f}}$ angle tests that could exploit sub-horizontal micro- and macro-fabric features. (d) The mean effective stresses developed during undrained shearing from $K_{0}$ values $>1$ fell when $\alpha_{\mathrm{f}} \leq 45^{\circ}$ and increased at higher $\alpha$ angles. These features reflected the clays' anisotropic micro-fabrics and stiffnesses.

(e) Relatively high peak $t / s^{\prime}$ and intermediate $S_{\mathrm{u}}$ values developed under low- $\alpha_{\mathrm{f}}$ conditions. These results are closely connected to curvature of the effective stress envelopes, as clearly seen in the London clay. This feature is likely to be observed for the other clays. For example, the Oxford clay developed limited tensile circumferential effective stresses in 'active' undrained $b=0.5$ tests with $\alpha_{\mathrm{f}}=0^{\circ}$.

( $f$ ) The clays' variations of peak $t / s^{\prime}$ and $S_{\mathrm{u}}$ with $\alpha_{\mathrm{f}}$ manifest significantly different patterns (Figs 13 and 16), reflecting the combined effects of: $(i) p^{\prime}$ changes during shear; (ii) the limited resistance to tensile stress; and (iii) $t / s^{\prime}$ reducing as $p^{\prime}$ increases.

(g) The relatively high peak $S_{\mathrm{u}}$ and intermediate $t / s^{\prime}$ values found at $\alpha_{\mathrm{f}}=90^{\circ}$ reflect the same factors as above $(i)-(i i i)$. The soil micro-fabric was relatively resistant to horizontal loading, with the micro-fabric leading to $p^{\prime}$ increases that depressed the mobilised $\phi^{\prime}$ applying in undrained 'passive' $\left(\alpha_{\mathrm{f}}=90^{\circ}\right) \mathrm{HCA}$ tests.

(h) The stiff clays' anisotropic shear strength and pre-failure stiffness characteristics have important implications for stability and ground movements.

(i) Further constitutive model development combined with programmes of rigorous numerical analysis are required to investigate how the experimentally observed behaviour will impact on specific geotechnical engineering applications.

( $j$ ) Current models that assume a circular bounding surface in the $\tau_{z \theta}-\left[\left(\sigma_{z}-\sigma_{\theta}\right) / 2\right]$ plane, such as standard Cam clay, Drucker-Prager models, and so on, cannot capture the skewed envelopes manifested by the four studied overconsolidated clays. Brosse (2012) explores potential routes through which the observed shear strength anisotropy may be characterised more realistically.

\section{ACKNOWLEDGEMENTS}

The authors acknowledge the Engineering and Physical Sciences Research Council (EPSRC) for their funding of the research described under grants EP/E029957/1 and EP/D506387/1 to the contributions made by the Imperial College technicians Alan Bolsher, Steven Ackerley and Graham Keefe, as well as their colleagues Professor Matthew Coop and Drs Clark Fenton, Ramtin Hosseini-Kamal and Stephen Wilkinson who undertook the geological and microfabric studies that underpinned the work described. They also acknowledge Dr Nguyen Anh-Minh's contribution to parallel series of London clay HCA tests. Although not discussed in this paper, Dr Anh-Minh's experiments provided a vital contribution to the earlier London clay study.

\section{NOTATION}

$B$ pore pressure coefficient

$b$ intermediate principal stress factor

$c^{\prime}$ effective cohesion

$e$ void ratio

$E_{\mathrm{v}}^{\prime}, E_{\mathrm{h}}^{\prime} \quad$ effective vertical and horizontal Young's moduli, respectively

$G_{\mathrm{hh}} \quad$ shear modulus in horizontal plane

$G_{\mathrm{hv}}, G_{\mathrm{vh}}$ shear moduli in vertical plane

$G_{z \theta}\left(=G_{\mathrm{vh}}\right) \quad$ shear moduli in vertical plane

$I_{1}, I_{2}$ first and second invariants of Cauchy stress tensor respectively

$J \quad$ generalised deviatoric stress $J=\sqrt{J_{2}}$ 
$J_{2} \quad$ second invariant of Cauchy deviatoric stress tensor

$K$ coefficient of earth pressure

$K_{0} \quad$ coefficient of earth pressure at rest

$K^{\prime} \quad$ drained bulk stiffness

$K_{\mathrm{p}}$ theoretical lower bound passive coefficient

$K_{0} \quad$ coefficient of earth pressure at rest

$p^{\prime}$ mean effective stress

$p_{0}^{\prime} \quad$ initial mean effective stress

$p_{\mathrm{e}}^{*}$ Horslev's equivalent pressure

$q$ deviatoric stress $\left(=\sigma_{1}^{\prime}-\sigma_{3}^{\prime}\right)$

$s^{\prime} \quad\left(\sigma_{1}^{\prime}+\sigma_{3}^{\prime}\right) / 2$

$S_{\mathrm{u}} \quad$ undrained shear strength

$t \quad\left(\sigma_{1}^{\prime}-\sigma_{3}^{\prime}\right) / 2$

$u$ pore water pressure

$\alpha$ angle between the vertical and the direction of $\sigma_{1}$ axis

$\alpha_{\mathrm{d} \sigma} \quad$ angle between the vertical and the direction of $\delta \sigma_{1}$ axis

$\alpha_{\mathrm{f}}$ angle between the vertical and the direction of $\sigma_{1}$ axis at peak $q$

$\gamma$ bulk unit weight

$\gamma_{z \theta}$ shear strain

$\varepsilon_{1}, \varepsilon_{2}, \varepsilon_{3}$ major, intermediate and minor principal strains, respectively

$\varepsilon_{z}, \varepsilon_{\mathrm{r}}, \varepsilon_{\theta} \quad$ axial, radial and circumferential strains, respectively

$\zeta$ mathematical variable used for parametric representation of stress path during constant $-\alpha_{\mathrm{d} \sigma}$ shearing stage

$\mu_{\mathrm{vh}}, \mu_{\mathrm{hv}}, \mu_{\mathrm{hh}}$ Poisson's ratios in the cross-anisotropic elastic model $\sigma_{1}, \sigma_{2}, \sigma_{3}$ major, intermediate and minor principal stresses, respectively

$\sigma_{z}, \sigma_{\mathrm{r}}, \sigma_{\theta}$ axial, radial and circumferential stresses, respectively $\phi^{\prime} \quad$ effective angle of shearing resistance

\section{REFERENCES}

Addenbrooke, T. I., Potts, D. M. \& Puzrin, A. M. (1997). The influence of pre-failure soil stiffness on the numerical analysis of tunnel construction. Géotechnique 47, No. 3, 693-712, http://dx.doi.org/10.1680/geot.1997.47.3.693.

Anh-Minh, N. (2006). An investigation of the anisotropic stressstrain-strength characteristics of an Eocene clay. $\mathrm{PhD}$ thesis, Imperial College London, London, UK.

Bishop, A. W. (1966). The strength of soils as engineering materials. 6th Rankine Lecture. Géotechnique 16, No. 2, 91-130, http://dx.doi.org/10.1680/geot.1966.16.2.91.

Brosse, A. M. (2007). Study of simple shear on natural London clay with a hollow cylinder apparatus. MSc dissertation, Imperial College London, London, UK.

Brosse, A. M. (2012). Study on the anisotropy of British stiff clays using a hollow cylinder apparatus. $\mathrm{PhD}$ thesis, Imperial College London, London, UK.

Brosse, A. M., Jardine, R. J. \& Nishimura, S. (2016). Undrained stiffness anisotropy from hollow cylinder experiments on four Eocene-to-Jurassic UK stiff clays. Can. Geotech. J, http://dx.doi.org/10.1139/cgj-2015-0320.

Brosse, A., Hosseini Kamal, R., Jardine, R. J. \& Coop, M. R. (2017). The shear stiffness characteristics of four Eoceneto-Jurassic UK stiff clays. Géotechnique 67, No. 3, 242-259, http://dx.doi.org/10.1680/jgeot.15.P.236.

Burland, J. B. (1990). On the compressibility and shear strength of natural clays. 30th Rankine Lecture. Géotechnique 40, No. 3, 329-378, http://dx.doi.org/10.1680/geot.1990.40.3.329.

Gasparre, A., Nishimura, S., Coop, M. R. \& Jardine, R. J. (2007a). The influence of structure on the behaviour of London Clay. Géotechnique 57, No. 1, 19-31, http://dx.doi.org/10.1680/geot. 2007.57.1.19.

Gasparre, A., Nishimura, S., Anh-Minh, N., Coop, M. R. \& Jardine, R. J. (2007b). The stiffness of natural London clay. Géotechnique 57, No. 1, 33-48, http://dx.doi.org/10.1680/geot.2007.57.1.33.

Gasparre, A., Hight, D. W., Coop, M. R. \& Jardine, R. J. (2014). The laboratory measurement and interpretation of the small strain stiffness of stiff clays. Géotechnique 64, No. 12, 942-953, http://dx.doi.org/10.1680/geot.13.P.227.

Hight, D. W. \& Jardine, R. J. (1993). Small strain stiffness and strength characteristics of hard London Tertiary clays. In Geotechnical engineering of hard soils-soft rocks (eds
A. Anagnostopoulos, F. Schlosser, N. Kalteziotis and R. Frank), vol. 1, pp. 533-552. Rotterdam, the Netherlands: Balkema.

Hight, D. W., Gens, A. and Symes, M. J. (1983). The development of a new hollow cylinder apparatus for investigating the effects of principal stress rotation in soils. Géotechnique 33, No. 4 355-384, http://dx.doi.org/10.1680/geot.1983.33.4.355.

Hight, D. W., Gasparre, A., Nishimura, S., Minh, N. A., Jardine, R. J. \& Coop, M. R. (2007). The influence of structure on the behaviour of London Clay. Géotechnique 57, No. 1, 3-18, http://dx.doi.org/10.1680/geot.2007.57.1.19.

Hoque, E., Tatsuoka, F. \& Sato, T. (1996). Measuring anisotropic elastic properties of sand using a large triaxial specimen. Geotech. Testing J. 19, No. 4, 411-420, http://dx.doi.org/ $10.1520 /$ GTJ10718J.

Hosseini Kamal, R. (2012). Experimental study of the geotechnical properties of UK mudrocks. $\mathrm{PhD}$ thesis, Imperial College London, London, UK.

Hosseini Kamal, R., Coop, M. R., Jardine, R. J. \& Brosse, A. (2014). The post-yield behaviour of four Eocene-to-Jurassic UK stiff clays. Géotechnique 64, No. 8, 620-634, http://dx.doi.org/ 10.1680/geot.13.P.043.

Jardine, R. J. (1985). Investigations of pile soil behaviour. $\mathrm{PhD}$ thesis, Imperial College, London, UK.

Jardine, R. J., Potts, D. M., Fourie, A. B. \& Burland, J. B. (1986). Studies of the influence of non-linear stress-strain characteristics in soil-structure interaction. Géotechnique 36, No. 3, 377-396, http://dx.doi.org/10.1680/geot.1986.36.3.377.

Jardine, R. J., Gens, A., Hight, D. W. \& Coop, M. R. (2004). Developments in understanding soil behaviour. Keynote paper. In Advances in geotechnical engineering: the Skempton conference (eds R. J. Jardine, D. M. Potts and K. G. Higgins), vol. 1, pp. 103-207. London, UK: Thomas Telford.

Jardine, R. J., Standing, J. R. \& Kovacevic, N. (2005). Lessons learned from full scale observations and the practical application of advanced testing and modelling. Keynote paper. In Deformation characteristics of geomaterials: recent investigations and prospects (eds $\mathrm{H}$. di Benedetto, T. Doanh, H. Geoffroy and C. Sauzéat), vol. 2, pp. 201-245. London, UK: Balkema.

Lo, K. Y. (1965). Stability of slopes in anisotropic soil. J. Soil Mech. Found. Div. ASCE 91, No. 4, 85-106.

Mayne, P. W. \& Kulhawy, F. H. (1982). Ko-OCR Relationships in Soil. J. Soil Mech. Found. Div. 108, No. 6, 851-872.

Minh, N. A., Nishimura, S., Takahashi, A. \& Jardine, R. J. (2011). On the control systems and instrumentation required to investigate the anisotropy of stiff clays and mudrocks through hollow cylinder tests. In Deformation characteristics of geomaterials (eds C.-K. Chung, H.-K. Kim, J.-S. Lee, Y.-H. Jung and D.-S. Kim), vol. 1, pp. 287-297. Amsterdam, the Netherlands: IOS Press.

Morgenstern, N. R. \& Tchalenko, J. S. (1967). Microstructural observation on shear zones from slips in natural clays. Proceedings of a geotechnical conference, Oslo, Norway, vol. 1, pp. $147-152$.

Nishimura, S. (2006). Laboratory study of the anisotropy of natural London Clay. PhD thesis, Imperial College London, London, UK.

Nishimura, S. (2014). Assessment of anisotropic elastic parameters of saturated clay measured in triaxial apparatus: appraisal of techniques and derivation. Soils Found. 54, No. 3, 364-376.

Nishimura, S., Minh, N. A. \& Jardine, R. J. (2007). Shear strength anisotropy of natural London Clay. Géotechnique 57, No. 1, 49-62, http://dx.doi.org/10.1680/geot.2007.57.1.49.

Nishimura, S., Jardine, R. J. \& Brosse, A. (2008). Simple shear testing of London Clay in hollow cylinder apparatus. In Deformational characteristics of geomaterials (eds S. E. Burns, P. W. Mayne and J. C. Santamarina), vol. 1, pp. 199-206. Amsterdam, the Netherlands: IOS Press.

Pietruszczak, S. \& Mroz, Z. (2000). Formulation of anisotropic failure criteria incorporating a microstructure tensor. Comput. Geotech. 26, No. 2, 105-112.

Potts, D. M. \& Zdravkovic, L. (2001). Finite element analysis in geotechnical engineering: application. London, UK: Thomas Telford. 
Potts, D. M., Dounias, G. T. \& Vaughan, P. R. (1990). Finite element analysis of the progressive failure of Carsington embankment. Géotechnique 40, No. 1, 79-101, http://dx.doi.org/10.1680/ geot.1990.40.1.79.

Potts, D. M., Kovacevic, N. \& Vaughan, P. R. (1997). Delayed collapse of cut slopes in stiff clay. Géotechnique 47, No. 5, 953-982, http://dx.doi.org/10.1680/geot.1997.47.5.953.

Viggiani, G. \& Hall, S. A. (2008). Full-field measurements, a new tool for laboratory experimental geomechanics. In
Deformational characteristics of geomaterials (eds S. E. Burns, P. W. Mayne and J. C. Santamarina), vol. 1, pp. 3-26. Amsterdam, the Netherlands: IOS Press.

Wilkinson, S. (2011). The microstructure of UK mudrocks. $\mathrm{PhD}$ thesis, Imperial College London, London, UK.

Zdravkovic, L., Potts, D. M. \& Hight, D. W. (2002). The effect of strength anisotropy on the behaviour of embankments on soft ground. Géotechnique 52, No. 6, 447-457, http://dx.doi.org/ 10.1680/geot.2002.52.6.447. 